Portland State University

PDXScholar

\title{
An Environment-based Education Approach to Professional Development: A Mixed Methods Analysis of the Creeks and Kids Watershed Workshop and Its Impact on K-12 Teachers
}

Tiffany Bridgette Austin

Portland State University

Follow this and additional works at: https://pdxscholar.library.pdx.edu/open_access_etds Let us know how access to this document benefits you.

\section{Recommended Citation}

Austin, Tiffany Bridgette, "An Environment-based Education Approach to Professional Development: A Mixed Methods Analysis of the Creeks and Kids Watershed Workshop and Its Impact on K-12 Teachers" (2010). Dissertations and Theses. Paper 103.

https://doi.org/10.15760/etd.103

This Thesis is brought to you for free and open access. It has been accepted for inclusion in Dissertations and Theses by an authorized administrator of PDXScholar. Please contact us if we can make this document more accessible: pdxscholar@pdx.edu. 
An Environment-based Education Approach to Professional Development: A Mixed

Methods Analysis of the Creeks and Kids Watershed Workshop and Its Impact on K-12

Teachers

by

Tiffany Bridgette Austin

A thesis submitted in partial fulfillment of the requirements for the degree of

Master of Science in Teaching

in

General Science

Thesis Committee:

William Becker, Chair

Linda Mantel

Cary Sneider

Portland State University

(C)2010 


\begin{abstract}
This research is an in-depth study of an environment-based education (EBE) professional development program titled "Creeks and Kids" that models how to employ thematic instruction about watersheds using the environment of a school and its community as a context to integrate teaching and learning about water across core subject areas. This case study investigates the EBE characteristics of the Creeks and Kids Workshop and explores how they adhere to the National Research Council's Standards for Professional Development for Teachers of Science. A mixed-methods analysis gathered qualitative data about the overall experience of teacher-participants during the Creeks and Kids Workshop and employed quantitative measures to identify evidence of success related to teachers' gains in knowledge, affect, confidence and intent to act to implement water-focused EBE curriculum in their classrooms. The findings of the study build upon existing research about what teachers need to implement EBE and their beliefs regarding what professional development should provide in relation to those needs. Qualitative results revealed that teachers need an EBE professional development program to include: 1) practical ways to integrate environmental education into their existing curricula and school settings; and, 2) direct experience with activities and field studies that are interdisciplinary, hands-on and inquiry-driven. Teacher-participants identified these characteristics as vital for them to effect a change in teaching practice and build their confidence to engage their students in EBE when they return to the classroom. Quantitative results revealed statistically significant gains across knowledge, affect, confidence and intent to act variables using
\end{abstract}


the t-test statistic to compare means of participants' responses from the pre- to postworkshop questionnaires. The results of this study have broader implications for future educational research on: 1) the ways in which EBE professional development programs can support teachers to gain the knowledge, skills and confidence to implement interdisciplinary teaching for student learning about the environment; 2) the methods teachers use to employ EBE teaching strategies in the classroom; and, 3) how EBE helps teachers across disciplines collaborate with one another to implement practical and effective ways to improve students' critical thinking skills and knowledge across multiple subjects. 


\section{DEDICATION}

I dedicate this work to Lin Howell. I was so fortunate to embark upon this journey and be witness to his passion to support and encourage the amazing teachers who guide the minds of students in the Pacific Northwest. Never have I met a person more humble in his gift to inspire others as he helps them to discover that the wings they need to fly have been there all along. 


\section{ACKNOWLEDGEMENTS}

In the spirit of science, I realize that I have truly lived a unique life cycle of many stages during my time as a graduate student in the Center for Science Education. I have been through a metamorphosis of thought, practice and action as this cycle has progressed. Though I know that this cycle is not yet complete, I recognize that I would not have come this far without the support of the people who have helped me during this transformation. I wish to thank Dr. William Becker for his honesty, understanding and support of the decisions I have made during my time as his student; Jennifer Wells, who served as my inspiration to carry out this work and has been a continued base of support; Dr. Cary Sneider, who has always cheered me on-especially during my times of doubt and confusion during this process; Jack Kirschenbaum, who has offered his time, kind words of encouragement and sage advice; and, finally, to Dr. Linda Mantel, who I am fortunate to call a mentor and a friend. She has supported me in so many ways to grow personally and professionally and helped me to open my mind toward countless possibility. Thank you all for believing in me. 


\section{TABLE OF CONTENTS}

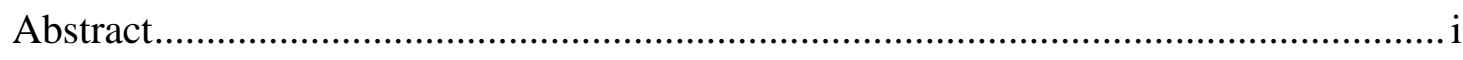

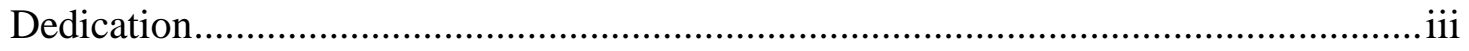

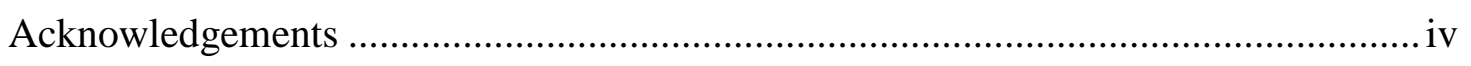

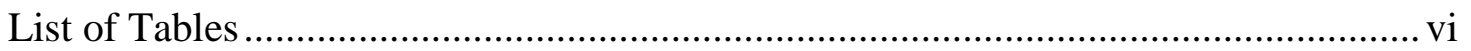

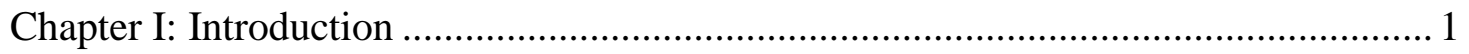

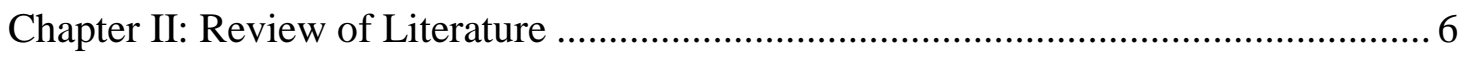

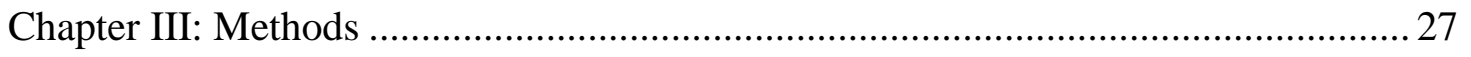

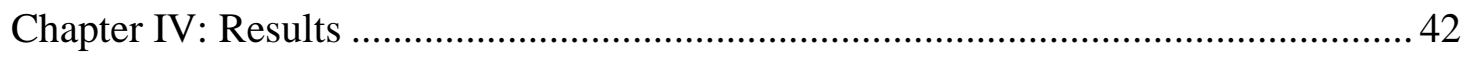

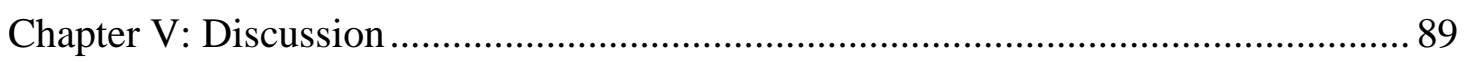

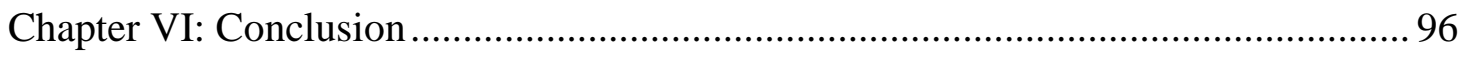

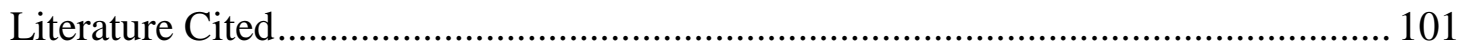

Appendix A: Demographics and Instructors' Backgrounds ................................... 105

Appendix B: Description of the Creeks and Kids Workshop ................................ 109

Appendix C: Qualitative Interview Forms, Protocols and Coding Description ......... 119

Appendix D: Creeks and Kids Pre- Post-Questionnaire ........................................ 132

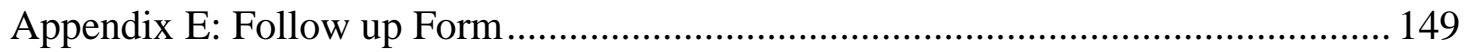

Appendix F: Creeks and Kids History and Grant Proposal .................................. 152

Appendix G: Human Subjects Protocols and Consent Forms ................................ 157 


\section{LIST OF TABLES}

Methods Section

Table 3.1: Demographic Characteristics of summer 2009 Creeks

and Kids Workshop Participants

Results Section

Table 4.1: Coded responses for "What were your primary motivations for attending the Creeks and Kids Workshop" 42

Table 4.2: Coded responses for "Aspects of the workshop that were most satisfying".....

Table 4.3: Coded responses for "What aspects of the workshop were most challenging and/or frustrating",

Table 4.4: Coded Responses for "Anticipated outcomes from attending the Workshop" 48

Table 4.5: Summary of coded responses for

"Did you share your Creeks \& Kids experience with any colleagues?" 52

Table 4.6: T-test Results for Knowledge Items 27-47. 65

Table 4.7: Frequency of recurring words and phrases for item 23

"List 2-3 ways in which you can contribute to watershed health and restoration" 67

Table 4.8: Statement Responses for Items 17-21 in Affect Category ......................... 68

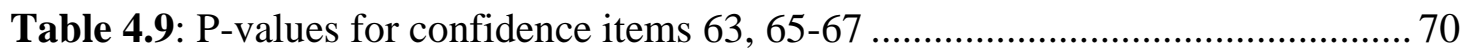

Table 4.10: P-values for Items 48-53 Intent to Act Responses .............................. 71

Table 4.11: Participant Responses to: "Please indicate with whom you have shared your experiences and/or curricula from the Creeks and Kids Workshop".... 74 


\section{Chapter I: Introduction}

The charge to create an awareness about water issues and empower people to effect change for sustainable water resource management may well be one the most important educational challenges of our age (Chitale and Cederwall, 2001). The United Nations World Water Assessment Programme (UNWWAP) indicates that the smooth functioning of ecosystems, communities and economies depends upon the availability of clean and safe freshwater supplies (UNWWAP, 2009). Solutions to protect water resources will be complex, and the ability to mitigate existing issues and prevent new ones will depend on a sensitivity to and knowledge of water that is cultivated through an environment-based education (EBE) (Ernst, 2009; Project WET, 1995). Research reveals some of the successes schools have had with EBE (Ernst 2007; 2009). By using the environment as a context to integrate core subject areas and real world learning experiences, EBE's interdisciplinary and collaborative approach promotes the development of the critical thinking and problem-solving skills that are vital for creating sustainable solutions to protect water resources and the environment (Disinger and Monroe 1994; Ernst 2009). The problem, however, is that lost in the myriad definitions of environmental education, there is a lack of understanding about what EBE is, how it should be implemented and what teachers need to support it in their classrooms.

This research is an in-depth study of an environment-based education (EBE) professional development program that uses the environment and the theme of water as an integrating context for learning. The goal of the program is to promote teachers' 
efficacy to teach EBE about water using inquiry-based, interdisciplinary lessons and field study where teachers collaborate and work in teams. The program, titled "Creeks and Kids", was a four-day summer intensive immersion workshop that provided a case study to illuminate the experiences of 14 teachers who participated in the program (program description found in Appendix B). The mixed-methods approach gathered qualitative information about the overall experience of participants and employed quantitative measures to identify evidence of success related to teachers' gains in knowledge, affect, confidence and intent to act to implement EBE curriculum about water.

Interdisciplinary, water-focused curriculum is not new to teachers. The nationally recognized lessons and activities from Project WET and Project WILD Aquatic are examples that have been available to formal and nonformal educators since the mid 1980's. The issue, however, is that curriculum is not always introduced in a way that teachers can readily use or makes sense of within their particular school settings (Gruver \& Luloff, 2008; Lieberman \& Hoody, 1998). Access alone, to even high quality interdisciplinary and thematic curricula, is rarely enough. Teachers need practical ways in which to implement lessons and activities that are relevant to their students in their individual classroom settings.

This study answers a call from the literature to explore the specific ways in which efficacy to teach about environmental education topics is increased (Moseley, Reinke \& Bookout, 2002). An examination of the Creeks and Kids program provides an opportunity to find out if an environment-based education professional development 
(EBEPD) model helps build that efficacy (Lieberman \& Hoody, 1998). While there are studies about successes of schools implementing EBE with students, there is a gap in the literature about successful examples of professional development models available for teachers to learn the instructional strategies of EBE as well as about models that influence teachers' confidence to implement EBE (Ernst 2007; 2009; Ernst \& Monroe, 2004; Lieberman \& Hoody, 1998). There is also little if any literature on how an EBE professional development program such as Creeks and Kids adheres to the National Research Council's Standards for Professional Development of Teachers of Science (NRC, 1996). By examining the ways in which the Creeks and Kids' EBE-focused approach to teaching about watersheds influences participants' ideas about teaching practice, it also adds to the literature relating to research on teachers' beliefs about thematic instruction across all subjects (science, mathematics, language arts and the social sciences) (Salyer \& Crawley,1995; Lumpe, Haney \& Czerniak, 2000; National Research Council, 1996).

The National Research Council (1996) indicates that the challenge of professional development is to create optimal collaborative learning situations in which the best sources of expertise link with the experiences and current needs of teachers. Professional development (PD) that emphasizes collaboration within an EBE model accomplishes this by connecting teachers to best practices of successful educators and the ways in which they collaborate to use the environment to teach across disciplines (Lieberman \& Hoody, 1998). Studies are showing that teachers believe PD workshops that are hands-on, interdisciplinary and encourage networking with other teachers are 
most useful (Meichtry \& Harrell, 2002). Many existing PD programs for teachers are still non-collaborative and lecture-based (Colbert, Brown, Choi \& Thomas, 2008;

Kilibarda, 2006; Kenney et. al, 2003; Roberts, 2010). They also tend to focus heavily on content knowledge, rather than creating a more balanced approach that includes methods to increase teacher efficacy and addresses the realities of teachers' individual needs. To effect a change in teaching efficacy, PD must depart from modeling top-down transfer of knowledge, lecture-style teaching and traditional views supporting textbookcentered curriculum (Little 1993, as cited in Supovitz \& Turner, 2000). Teachers' needs are evolving, and these needs include learning new ways to deliver interdisciplinary curriculum through inquiry and field study. It is hoped that the findings of the current study will help inform research on what factors best support teachers to implement EBE, so that professional development can catch up to the evolving needs of the teachers who are guiding the minds of today to become the critical thinkers and problem solvers of the near future.

The following research question was used for this case study to find out about the nature of the Creeks and Kids program, teachers' needs to implement EBE in the classroom and their beliefs regarding what professional development should provide in relation to those needs:

What were the experiences of the teacher participants during the Creeks and Kids Watershed Education workshop and how did those experiences influence their knowledge, affect, confidence and intent to act to implement EBE in their schools? 
This question was answered with qualitative data from pre- and post-workshop questionnaires, researcher observations of teacher-participants and workshop instructors, and conversations and interviews with teacher-participants and workshop instructors. Quantitative variables were also measured using the pre- and post-workshop questionnaire to assess if there were statistically significant gains across categories of participants' knowledge, affect, confidence and intent to act relating to the interdisciplinary EBE water curriculum and instruction from the program.

This thesis is organized into the following chapters:

- Chapter II: A review of the literature, definition of concepts related to environment-based education (EBE), outline of the National Research Council's Standards for Professional Development of Teachers of Science and a review of EBE-related case studies;

- Chapter III: Demographic characteristics of the teacher participants and an outline of the methodological research design;

- Chapter IV: The results of the study;

- Chapter V: A discussion of the results, their relationship to previous literature and the broader implications of this research; and,

- Chapter VI: Conclusions and recommendations for future research. 


\section{Chapter II: Review of Literature}

\section{Thematic Instruction about Water}

In their book titled Investigating Streams and Rivers, Stapp, Cromwell, Schmidt and Alm (1996) assert that a watershed-wide approach toward learning about water resources and water systems connects teachers, students and classrooms with a shared sense of place and an awareness of local ecology. In addition, the authors emphasize that watershed education supports students to understand a world that is interconnected and interdependent, empowering them to learn about the issues that affect their local environment while helping them develop a global, cross-cultural perspective (Stapp et. al, 1996). How exactly does this occur? Stapp et. al (1996) explain by highlighting the benefits of watershed education:

1. By understanding their watershed, students learn that the different ways humans use land affects water resources.

2. By building a community of watershed-wide learning, sharing goes beyond the walls of the classroom to facilitate active learning, participation and communication skills that are essential and apply in the real world.

3. Cross-cultural sharing and understanding occurs when students realize the water's nature to flow through many areas, including suburban and urban. Students can learn about and communicate with people of a variety of backgrounds, lifestyles and experiences from these areas while learning about the commonalities and differences between people and landscapes throughout the watershed. 
In addition to connecting people and places, teaching about water provides a way for education to move toward a learning experience that is integrated and multidisciplinary. Using the theme of water and watersheds provides clear examples of concepts that are useful to bridge the traditional disciplines of science, such as biology and chemistry, with those of social studies, mathematics, and art. (Brody, 1995). Stapp (2000) explains the reasons behind using rivers as a main topic in water education to support curricula and instructional strategies that emphasize the global component of local environmental issues:

Rivers were selected as the central focus of this global, experiential, interdisciplinary, action-taking approach because rivers are a reliable and informative index of environmental quality of our land. Rivers also form a natural link for relating chemistry to biology and the physical sciences to the social sciences and humanities.

The changing landscape of education in Pennsylvania provides an example of this shift towards multidisciplinary learning. The Pennsylvania Department of Education required in 2002 that watershed education be taught in Pennsylvania's public schools, heeding research that revealed that there is a nationally recognized necessity to educate students about watersheds and water quality (Swann, 2000, as cited in Gruver and Luloff, 2008). In addition, Pennsylvania public schools have incorporated the watershed curriculum outcomes in its standardized testing to measure student achievement in Grades 4, 7, 10, and 12 (Gruver \& Luloff, 2008).

Stapp (2000) references the work of Paul F-Brandwein to further support the use of watershed education to benefit students so that they become active learners and 
active citizens who understand the issues related to water quantity and quality.

Brandwein, a scientist and teacher, believed that students should be:

- Grounded in all areas of the curriculum;

- Linked to real life experiences;

- Provided school and community interaction;

- Experienced in individual and group investigations;

- Problem solvers, not problem doers;

- Persistent in seeking explanations;

- Allowed the time to think and seek solutions;

- Mentored to work toward responses; and

- Informed at the local and global level.

By using water as an integrating theme in curricula, the learning outcomes Brandwein highlights become accessible. Stapp (2000) states:

Students come to experience the value of science, mathematics, and technological knowledge as they engage in their practical application when monitoring and analyzing the watershed. It is through direct learning experiences that students are more likely to recognize the relevance of science for improving their own lives, be able to adapt better to an increasingly technological world, and contribute to resolving science-technology-society issues responsibly.

This analysis of thematic instruction about water sets up the principles, goals and strategies behind environment-based education (EBE). This section and the EBE section of the literature review help set the stage for Creeks and Kids, a program that not only uses water as an integrating theme, but also uses many of the principles of EBE in its approach to professional development. 


\section{Environment-based Education}

Environment-based education (EBE) builds upon the principles and examples laid out in the previous section on thematic instruction. Research is revealing the positive impact on schools (administrators, teachers, students and parents) that EBE implementation strategies have (Ernst \& Monroe, 2004; Lieberman \& Hoody, 1998). In addition to defining what environment-based education (EBE) is, this section of the literature review also defines EBE within the context of what teachers need in professional development. In a later section of this literature review, the Standards for Professional Development for Teachers of Science (National Research Council, 1996), which call for many of the same approaches inherent in EBE, are outlined to serve as a basis of comparison to understand how closely the EBE curriculum and instruction of Creeks and Kids relate to the Standards.

The North American Association for Environmental Education (NAAEE) and the National Environmental Education \& Training Foundation (NEETF) created a research guide titled Using Environment-based Education to Advance Learning Skills and Character Development (2001). In this guide, the relationship between EBE and environmental education is explained:

Environment-based education is used to focus attention on the numerous benefits that arise from using the environment more broadly as a learning tool in schools and after-school programs. While environmental education focuses on building a base of environmental knowledge and skill to be applied to environmental stewardship, environment-based education uses a popular subject matter to improve students' learning skills and create a wider learning context for students, teachers and the community. Environment-based 
education emphasizes interdisciplinary integration of subject matter, problemand issue-based learning experiences, team teaching, learner-centered instruction, constructivist approaches and self-directed learning. A similar term, "environment as an integrating context" (EIC) is used by the State Education and Environment Roundtable (SEER) to describe this approach. (NAAEE \& NEETF, 2001).

Environment-based education is a strategy that casts a wide net to improve teaching and learning about science and the environment. Research shows that it is also useful in cultivating a student-centered approach to standards-based learning (NAAEE \&NEETF, 2001). Klein (1995) and Volk and McBeth (1998) assert that students who experience interdisciplinary as well as issues-based environmental education make significant gains in cognition and skills. Many teachers still do not have much exposure to research that supports the successes of EBE, and the findings of Kearney (1999) highlight that many teachers are not aware of the possibilities EBE presents for gains in student achievement.

Professional development opportunities that expose teachers to research and allow them to directly engage in the strategies used in EBE could help this approach to environmental education to become more widely accepted in the classroom. In addition, research such as that of Klein (1995), Volk and McBeth (1998) that connects environment-based education to improved test scores and grade level achievement could help bring a greater focus on EBE in teacher preparation programs in colleges and universities.

Though not peer-reviewed, a key study performed by Lieberman and Hoody (1998) lends great insight into the successes of environment-based education models in 
K-12 classrooms across the country. Lieberman and Hoody (1998) report on the State Education and Environment Roundtable, made up of education agencies from 12 states, which was a collaboration to improve student learning by integrating the environment into K-12 curricula and school reform efforts. The Roundtable headed a research effort to explore the potential of environment-based education (EBE) to change ineffective pedagogical paradigms and improve student learning by promoting critical thinking and problem-solving skills (Lieberman \& Hoody, 1998). The goal of EBE is to use the Environment as an Integrating Context for learning (EIC)—-terms previously mentioned that encompass the educational practices that the Roundtable believes should form the foundation of EBE programs in U.S. schools (Lieberman \& Hoody, 1998). However, for the purposes of this paper, environment-based education (EBE) will be the term used to describe the Creeks and Kids Workshop.

The EBE model takes into account that the ecosystems surrounding schools and their communities vary greatly. The term "environment" means different things to different people depending on the landscapes with which they are most familiar (Lieberman \& Hoody, 1998). The topic of water as it relates to the environment around a school could connect to a range of landscapes depending on the geographic location of the school-everything from the characteristics of the ocean or a nearby river to where water runs off and collects during a storm in a more urbanized and impervious terrain. In EBE, the school and its community's environment are a context for integrating core subject areas and a source of real-world learning experiences (Ernst, 2007). The Creeks and Kids Workshop adheres to these principles of EBE in its approach to professional 
development, showing teachers how they can use the environment of their schools and communities to create interdisciplinary and issues-based learning opportunities for students to understand water and watersheds.

Research is growing on how EBE impacts students. Lieberman \& Hoody's (1998) extensive research on 40 schools implementing EBE indicates that students show:

- increased performance on standardized measures of academic achievement in math, reading, writing, science and social studies;

- a reduction in discipline and classroom management problems;

- increased engagement and enthusiasm for learning; and,

- greater pride and ownership in accomplishments.

In addition, EBE studies are revealing that students make incredible gains in critical thinking skills compared to their traditionally schooled peers (Lieberman \& Hoody, 1998). Out of the 40 study schools, Lieberman and Hoody compiled data from a variety of sources (comprehensive and subject matter specific tests, standardized tests, grade point averages, student attitude measures, disciplinary actions, attendance) from 14 of the schools to find that these EBE students earned higher grades and dramatically increased their scores on standardized tests (1998). In summary, the EBE students outperformed their peers who were not involved in EBE across all disciplines. Teachers and administrators who participated in the study spoke to the academic gains, increased 
student engagement and longer student retention of knowledge that they attributed to the practice of EBE.

While environment-based education (EBE) is gaining ground in many schools across the country, it is still not the instructional norm. There are many factors surrounding why EBE is not widely used, but for the purposes of the present study, the focus is on the lack of opportunity for teachers to participate in professional development that engages teachers in EBE. This relates to the National Research Council's (NRC) criteria in their Professional Development Standards for Teachers of Science that if reform is to be accomplished, professional development must include experiences that engage prospective and practicing teachers in active learning that builds their knowledge, understanding, and ability (1996). The Lieberman \& Hoody (1998) study is an excellent and extensive report on the successful results from implementing EBE in schools. However, it does not point the reader to successful examples of professional development models available for teachers to learn the instructional strategies of EBE so that they might experience the active learning as described by the NRC and model this with their students.

Ernst (2007) reveals that according to a study by the National Consortium for Environmental Education and Training, professional development in environmental education for in-service teachers has been primarily science-oriented rather than interdisciplinary and is focused more on environmental content than on the use of environment as an instructional strategy as practiced in EBE. In addition, Ernst asserts that much of the available environmental education curricula are highly science- 
oriented (2007). This is not to imply, however, that science is not an important focus of learning or professional development. An important part of this Creeks and Kids case study is to relate how much the program adheres to the National Research Council's Professional Development Standards for Teachers of Science. These Standards specifically highlight how the current reform effort in science education requires a substantive change in how science is taught, and, that implicit in this reform, is an equally substantive change in professional development practices at all levels (NRC, 1996). However, teachers' efforts to learn EBE curriculum and teaching practices will not be served by professional development using curriculum and instruction that only occasionally infuses EBE into science instead of using the environment as a context to integrate and show the relationships between multiple disciplines, including science, on a regular basis (Ernst, 2007; 2009). Ernst also reveals that, based on the research of Simmons (1993) that shows most teachers see natural settings as primarily science or recreation-based opportunities, there is a lack of awareness teachers have to use their local environments as contexts to integrate core subject areas (2007).

The EBE approach, if applied in professional development models, has the potential to address the issues as laid out by Ernst (2007) and Simmons (1993) as it:

- breaks down traditional boundaries between disciplines;

- provides hands-on learning experiences, often through problem-solving and project-based activities;

- relies on team teaching; 
- allows teachers to adapt to individual students and their unique skills and abilities; and,

- fosters knowledge of and an understanding and appreciation for a school's local environment and community (Lieberman \& Hoody, 1998).

Roberts' (2010) research on professional development (PD) programs had this to contribute:

Teachers have become accustomed to professional development programs that require them to sit and have an outsider tell them what is best for their students. Often they take part in one- or two-day training sessions with teachers who not only use different curriculums, but also serve very different audiences of students, leaving teachers frustrated and unable to learn the strategies they need for their own classroom practice.

The bullet points regarding the potential for an EBE approach to enrich teachers' professional development (PD) experiences as they relate to environmental education speak directly to the issues Roberts has uncovered. An EBE professional development approach could address these issues resulting from current one-size-fits-all PD models. The study of water in and around a local school environment can connect teaching within the sciences (chemistry, geology, physics) and across disciplines (science, language arts, social studies) when used within an EBE framework. If PD models use the environment as an integrating context, they could more effectively support teachers from both similar and different disciplines to collaborate toward common instructional goals. 


\section{The Standards for Professional Development for Teachers of Science from the National Research Council}

The National Science Education Standards aim to advance a scientifically literate society (NRC, 1996). While the Standards focus on many principles, definitions and practices, they promote a message of reform for the many professional development programs that currently lack strategies on how to teach and understand science as inquiry:

Implicit in this reform is an equally substantive change in professional development practices at all levels... much current professional development involves traditional lectures to convey science content and emphasis on technical training about teaching. If reform is to be accomplished, professional development must include experiences that engage prospective and practicing teachers in active learning that builds their knowledge, understanding and ability. The vision of science and how it is learned as described in the Standards will be nearly impossible to convey to students in schools if the teachers themselves have never experienced it. Simply put, pre-service programs and professional development activities for practicing teachers must model good science teaching. (NRC, 1996).

Perhaps the most important piece of this quote is that the Standards for professional development can be written with the best of intentions; however, if teachers do not have accessible opportunities to practice active learning and inquiry, this type of learning will never be passed on to students.

The Professional Development Standards for Teachers of Science, highlighted below, set up a framework for analysis of how the curriculum and instructional approach of the Creeks and Kids program adheres to these Standards. Standards A through D are taken directly from the National Research Council Standards list (1996). 


\section{Professional Development Standard A}

Professional development for teachers of science requires learning essential science content through the perspectives and methods of inquiry. Science learning experiences for teachers must:

- Introduce teachers to scientific literature, media, and technological resources that expand their science knowledge and their ability to access further knowledge.

- Build on the teacher's current science understanding, ability, and attitudes.

- Incorporate ongoing reflection on the process and outcomes of understanding science through inquiry.

- Encourage and support teachers in efforts to collaborate. (NRC, 1996).

\section{Professional Development Standard B}

Professional development for teachers of science requires integrating knowledge of science, learning, pedagogy, and students; it also requires applying that knowledge to science teaching. Learning experiences for teachers of science must:

- Connect and integrate all pertinent aspects of science and science education.

- Occur in a variety of places where effective science teaching can be illustrated and modeled, permitting teachers to struggle with real situations and expand their knowledge and skills in appropriate contexts.

- Address teachers' needs as learners and build on their current knowledge of science content, teaching, and learning. 
- Use inquiry, reflection, interpretation of research, modeling, and guided practice to build understanding and skill in science teaching. (NRC, 1996).

\section{Professional Development Standard C}

Professional development for teachers of science requires building understanding and ability for lifelong learning. Professional development activities must:

- Provide regular, frequent opportunities for individual and collegial examination and reflection on classroom and institutional practice.

- Provide opportunities for teachers to receive feedback about their teaching and to understand, analyze, and apply that feedback to improve their practice.

- Provide opportunities for teachers to learn and use various tools and techniques for self-reflection and collegial reflection, such as peer coaching, portfolios, and journals.

- Support the sharing of teacher expertise by preparing and using mentors, teacher advisers, coaches, lead teachers, and resource teachers to provide professional development opportunities.

- Provide opportunities to know and have access to existing research and experiential knowledge.

- Provide opportunities to learn and use the skills of research to generate new knowledge about science and the teaching and learning of science. (NRC, 1996).

\section{Professional Development Standard D}

Professional development programs for teachers of science must be coherent and integrated. Quality pre-service and in-service programs are characterized by: 
- Clear, shared goals based on a vision of science learning, teaching, and teacher development congruent with the National Science Education Standards.

- Integration and coordination of the program components so that understanding and ability can be built over time, reinforced continuously, and practiced in a variety of situations.

- Options that recognize the developmental nature of teacher professional growth and individual and group interests, as well as the needs of teachers who have varying degrees of experience, professional expertise, and proficiency.

- Collaboration among the people involved in programs, including teachers, teacher educators, teacher unions, scientists, administrators, policy makers, members of professional and scientific organizations, parents, and business people, with clear respect for the perspectives and expertise of each.

- Recognition of the history, culture, and organization of the school environment.

- Continuous program assessment that captures the perspectives of all those involved, uses a variety of strategies, focuses on the process and effects of the program, and feeds directly into program improvement and evaluation. (NRC, 1996).

These Standards are important to highlight since they reflect many of the previously mentioned aspects of an environment-based education (EBE) approach. Since this thesis research aims to show that the Creeks and Kids Workshop employs EBE methods, the results of this study can be analyzed in relation to how closely Creeks and Kids as an EBE professional development workshop adheres to these Standards for Professional Development for Teachers of Science. 


\section{Current Case Studies of Environmental Education Professional Development (EEPD)}

This section describes some current case studies on EEPD and highlights any of their environment-based education (EBE) characteristics. These cases demonstrate a variety of levels at which EEPD programs address the issue of teacher efficacy surrounding the skills and knowledge to implement environmental education (Young \& Simmons, 1992). The methods of these studies also provided a framework on which to choose appropriate methodology for the Creeks and Kids study.

Shepardson, Harbor, Cooper \& McDonald (2002) reported on a professional development model that engaged teachers in investigating the environment by designing and carrying out their own environmental research projects. The program consisted of two phases: 1) a pre-institute workshop that allowed teachers to become familiar with their local watersheds where they would conduct their research; and 2) a 2-3 week long summer institute that introduced participants to methods on stream and water quality monitoring, and the identification of macroinvertebrates and invasive plant species.

The authors hypothesized that the professional development process would instill teachers with a sense of increased knowledge, skills and confidence to conduct environmental investigations in their own classroom teaching. The results of the study supported part of the hypothesis, revealing that professional development programs that engage teachers in research-based field studies positively affect their knowledge and understanding of environmental science concepts and issues as well as their abilities to conduct environmental monitoring projects. An interesting finding of the study was that 
the program's focus on watersheds greatly impacted teachers' understanding of how stream quality is linked to land-use patterns, helping them realize that watersheds are holistic and biological systems. Another conclusion that Shepardson et. al (2002) highlight is that techniques modeled in a professional development program will be the ones that teachers will adapt and use with their students.

What the study fails to produce, however, is specific evidence of teacher efficacy to implement water-focused environmental field study in their educational settings. There is no bridge to support the claim that knowledge gains of participants from pre-test to post-test provided them with anything else but the tools to recreate the techniques learned in the program. Outside of the original hypothesis, there is no mention of confidence gain from either quantitative measures or qualitative coded data from surveys. It is not clear from the study that teacher-participants would have the confidence to adapt what was learned during this professional development program to the ever-changing demands and realities within their own classrooms. This study served as an example of a gap in the literature surrounding teachers' confidence to implement EE. There is also no mention of how the teachers' experiences connect to any professional development standards.

A study by Kenney, Militana \& Donohue (2003) clearly identifies salient factors that contributed not only to the success of a watershed environmental education professional development program, but also to the increased efficacy of the participants to adapt curriculum and teach it within their educational settings. The researchers performed a mixed methods analysis of a 3-year implementation of The Watershed 
Learning Center's (WLC) environmental education program within 15 schools. To get a complete picture of the program, they collected data via observations, surveys, interviews, document analysis and written narratives from a variety of participants including the teacher-participants, Watershed Learning Center staff, school administrators and students. These data collection methods inspired the research design of the Creeks and Kids study.

The overall goal of the WLC program is to provide outdoor environmental education lessons and activities for teachers and students to do on school grounds and other outdoor areas within walking distance of the school. These particular goals closely align with those of an environment-based education (EBE) model, which includes the Creeks and Kids Workshop.

The reasons identified that made the adoption of the WLC program successful were: 1) the teachers were already enthusiastic about environmental education and advocated within their schools for the program;2) the program was a supplement to existing curriculum and was not mandatory, so teachers were able to work with WLC staff to customize curriculum based on individual needs; and 3) an ongoing support network was established for teachers to connect and collaborate with other teachers as well as for teachers to continually work with WLC staff members.

Colbert, Brown, Choi \& Thomas (2008) highlight how the customization of a professional development program's curriculum to meet the needs of individual teachers is important: 
Professional development is a common and necessary approach to improving teacher quality. However, while teachers are required to participate in professional development activities, it is often the case that they are not involved in selecting and planning those activities, and that the professional development may not be closely tied to classroom practice.

The factors lending evidence that the Watershed Learning Center environmental education (EE) program had a positive impact on teacher-participants included the high quality of the lessons and activities, the high quality of WLC instructors, and the amount of time allocated to outdoor field study lessons. All of these factors resulted in an increase in participating teachers' perceived ability and confidence to teach EE. This confidence was especially strengthened from teachers' mention that the WLC staff not only provided great support when needed during the program, but they also provided teachers with support after the program was finished, making teachers feel that they were not left to "sink or swim" after training. The strength of this study's qualitative methods that provided such in-depth results were important to recognize for the purposes of the Creeks and Kids study which sought to reveal a similar in-depth picture of a professional development program.

Moseley, Reinke \& Bookout (2002) researched an EE program titled "Adventures Beyond the Classroom" (ABC) to determine if the program has an effect on teachers' self-efficacy. Moseley et. al (2002) define self-efficacy as the teacher's belief that he or she can teach environmental education (EE). Though the authors do not give detailed information about the $\mathrm{ABC}$ program, they do indicate that it was a 3-day 
outdoor education program designed to allow pre-service elementary teachers to design, plan and teach EE lessons in an outdoor setting. Their study was a strictly quantitative study that employed the Environmental Education Efficacy Belief Instrument, which uses a 5-point Likert scale response system. The results of the study showed that the effect of the $\mathrm{ABC}$ program was not statistically significant. In addition, the researchers administered a second post-test 7 weeks later, which showed a significant drop in selfefficacy.

The research of Moseley et. al (2002) does not offer direct evidence as to why there was a lack of statistical significance in either the first post-test or the second posttest. It is, of course, a common reality in research that one cannot always get the complete answers to a research question from just one study. However, a mixed methods approach that included direct feedback from the teachers involved in the $\mathrm{ABC}$ program could have provided better insight into the initial lack of change in efficacy and the later decrease that was measured. This also influenced the approach of the current Creeks and Kids study to employ a mixed-methods analysis that could show supporting evidence and patterns between quantitative and qualitative data.

Although this is by no means an exhaustive review of EEPD models, these studies, in addition to the literature, provided at least an initial but well-rounded view of the current state of EEPD. The research on using water in thematic instruction and on the definitions and methods of environment-based education (EBE) provided a 
foundation on which to build a case study of the Creeks and Kids program and evaluate it as an EBE professional development experience.

According to Giolitto and Souchon (1996), environmental education (EE) is still a marginalized field because of its weak role in the official classroom curricula, the unfortunate compartmentalization of the education system, the failure to include EE among the subjects for examination and the poor preparation of teachers through proper programming and professional development opportunities. The goal of an environmentbased education (EBE) approach with thematic instruction as a form of EE is to teach environmental topics that bridge all subjects in the classroom. As Brody (1995) states:

If education is to move into an integrated and holistic mode, we must seek clear examples of concepts that can be used to bridge the so-called traditional disciplines such as biology, chemistry, social studies, mathematics, and art. Water provides such an example... there is empirical evidence that there exists in the field of water and water resource education a body of knowledge that is distinct from that embodied in traditional education programs. Among the most important characteristics are interdisciplinarity, relevance and integration of concepts, skills, and affect.

Creeks and Kids uses the environment-based education (EBE) approach that sets teachers up for success to teach water and watershed concepts across disciplines. Environmental topics, such as those related to water and watersheds, hold an intrinsic interest for students, especially when aimed close to home (NAAEE \& NEETF, 2001). Creeks and Kids starts out on day one by having teachers connect to their own story about water. This, in turn, helps teachers to understand that each of their students also has a special story about water. According to Creeks and Kids, if a student can connect 
to a particular topic through personal experience and one's surroundings, he or she is more likely to be able to learn and understand more about that topic. Learning about a problem with a local creek or wetland may be easier because it is more relevant to a student than if it were a faraway and unknown place (NAAEE \& NEETF, 2001). For students engaged in locally relevant environment-based studies, the abstract quickly becomes real through the immediate examples available in one's own school and community surroundings (NAAEE \& NEETF, 2001). 


\section{Chapter III: Methods}

This research is an in-depth study of an environment-based education (EBE) professional development program, titled "Creeks and Kids", that uses water as an integrating context for learning across disciplines. The research question that embodies the purpose of this case study to find out about the nature of the Creeks and Kids program, teachers' needs to implement EBE in the classroom and their beliefs regarding what professional development should provide in relation to those needs was:

What were the experiences of the teacher participants during the Creeks and Kids Watershed Education workshop and how did those experiences influence their views on their teaching practice as it relates to implementing EBE in their schools?

A mixed-methods approach included a qualitative description of participants' experiences during the workshop and a quantitative measurement of the program's success in helping participants meet learning outcomes and goals. Qualitative data related to the purpose of the study was acquired through researcher observations of teacher-participants and workshop instructors during the workshop, field notes and informal conversations and interviews with teacher-participants and instructors during and after the program. Quantitative data was gathered through a pre- post-workshop questionnaire to assess if participants exhibited gains in:

- knowledge of watershed education concepts;

- affect about environmental education and watershed stewardship; 
- confidence in ability to implement inquiry-based watershed education curriculum and field study; and,

- intent to implement inquiry-based teaching practices and engage learners in environmental education curriculum from their experience at the Creeks and Kids Workshop.

These gains were determined by performing a statistical analysis of participant response averages from pre- to post-workshop questionnaire. The complete questionnaire can be found in Appendix D.

This mixed methods approach helped to create a close representation of the Creeks and Kids workshop and establish validity of findings through data triangulation from a variety of data sources (Newman and Benz (1998), as cited in Leech \& Onwuegbuzie, 2007). Creswell (2007) asserts that by combining quantitative and qualitative data through a mixed methods analysis, trends and generalizations as well as a deeper knowledge of participants' perceptions and experiences can be captured to reveal a more complete picture of an event or process. A mixed methods analysis that examines the quantitative aspects that measure participants' mastery of objectives and goals coupled with qualitative interviews, observations and field notes was deemed the best way to find out if and how the Creeks and Kids workshop answers the research question of this study. As Creswell (2007) puts it, one type of evidence (quantitative or qualitative) may not reveal the full story behind the phenomenon, justifying the need for a more comprehensive mixed methods analysis. 
In summary, the mixed methods analysis was used to address the potential limitations of a single-method study. The combination of quantitative and qualitative data allows for a research opportunity to discover similar or dissimilar patterns within the data. In addition, the qualitative data gathered allowed respondents to describe their experiences or thoughts in a way that a quantitative value, such as a Likert number, cannot (Esterberg, 2002). This creates the potential for a richer data set overall.

\section{Participants}

The Creeks and Kids Workshop is advertised throughout the year on the Jackson Bottom Wetlands Preserve (JBWP) website. In addition, Creeks and Kids is advertised by the JBWP Teacher Education Specialist during other wetland education and environmental education workshops such as the Project Webfoot and Project WET workshops throughout the year prior to the July Creeks and Kids Workshop.

Creeks and Kids is run by the Teacher Education Specialist of Jackson Bottom Wetlands Preserve (JBWP), naturalists and watershed education specialists from JBWP, current and retired K-12 biology and general science educators, and Salmon and Trout Enhancement Program (STEP) biologists. The Workshop is paid for and sponsored by the Oregon Department of Fish and Wildlife's Restoration and Enhancement (ODFW) program. Every year grant funding is sought from ODFW Restoration and Enhancement so that the weeklong program can stay at an affordable cost for participants (around $\$ 35-40$ per participant). 
Participants were initially introduced to this study in May 2009 by an email that was drafted by the Jackson Bottom Wetlands Preserve (JBWP) Teacher Education Specialist. This email introduced the researcher and gave an overview of the goals of the study. The email message was sent out the entire group of 30 educators who had signed up to attend the summer 2009 Creeks and Kids Workshop. The Teacher Education Specialist verbally notified the six Creeks and Kids Workshop instructors of the study. The Teacher Education Specialist introduced the researcher to all instructors and study participants on the first day of the workshop.

All participants for this case study were recruited through convenience sampling to form a volunteer sample of participants who were easily accessible and willing to be a part of this study (Creswell \& Plano Clark, 2007). Out of the 30 educators signed up to attend the 2009 Creeks and Kids Workshop, a convenience sample of 14 volunteered to participate in this study. Six Creeks and Kids instructors comprised an additional convenience sample for qualitative data collection (field notes, observations and informal conversations) during and after the workshop. Four of the six instructors participated in phone interviews with the researcher post-workshop.

All participants for this study received official consent forms as designated by Portland State University's Human Subjects Research Review Committee either in person or by mail. Signatures of consent were obtained and mailed back to the researcher. Consent forms and Human Research Subjects protocols are in Appendix G. 
Table 3.1 shows some initial demographic characteristics of the teacherparticipants of the summer 2009 Creeks and Kids Workshop. Of the 14 participants, 13 were female, comprising $93 \%$ of the group. There was one $(7 \%)$ male participant in the group. The age brackets of the participants ranged from 21-30 years to over 60 years of age. Of the 14 participants, $72 \%$ total were in the age brackets of $41-50$ years $(36 \%)$ and $51-60$ years $(36 \%)$ of age.

Table 3.1: Demographic Characteristics of summer 2009 Creeks and Kids Workshop Participants $(n=14)$

\begin{tabular}{|c|c|c|c|c|c|}
\hline $\begin{array}{c}\text { Demographic } \\
\text { Variable }\end{array}$ & $\begin{array}{c}\text { Value } \\
(\%)\end{array}$ & $\begin{array}{c}\text { Value } \\
(\%)\end{array}$ & $\begin{array}{c}\text { Value } \\
(\%)\end{array}$ & $\begin{array}{c}\text { Value } \\
(\%)\end{array}$ & $\begin{array}{c}\text { Value } \\
(\%)\end{array}$ \\
\hline Age & $\begin{array}{c}21-30 \\
(7 \%)\end{array}$ & $\begin{array}{c}31-40 \\
(14 \%)\end{array}$ & $\begin{array}{c}41-50 \\
(36 \%)\end{array}$ & $\begin{array}{c}51-60 \\
(36 \%)\end{array}$ & $\begin{array}{c}\text { Over } 60 \\
(7 \%)\end{array}$ \\
\hline Gender & $\begin{array}{c}\text { Female } \\
(93 \%)\end{array}$ & $\begin{array}{c}\text { Male } \\
(7 \%)\end{array}$ & & & \\
\hline Ethnicity/Race & $\begin{array}{c}\text { White/Non } \\
- \text { Hispanic } \\
(93 \%)\end{array}$ & $\begin{array}{c}\text { Bispanic/White } \\
(7 \%)\end{array}$ & & & \\
\hline $\begin{array}{c}\text { Educational } \\
\text { Degree Earned }\end{array}$ & $\begin{array}{c}\text { Bachelors } \\
(100 \%)\end{array}$ & $\begin{array}{c}\text { Masters } \\
(79 \%)\end{array}$ & & & \\
\hline $\begin{array}{c}\text { Years } \\
\text { Teaching } \\
\text { Science }\end{array}$ & $\begin{array}{c}0-5 \text { years } \\
(57 \%)\end{array}$ & $\begin{array}{c}6-10 \text { years } \\
(14 \%)\end{array}$ & $11-15$ years \\
$(14 \%)$ & $16-20$ years \\
$(7 \%)$ & $\begin{array}{c}>20 \text { years } \\
(7 \%)\end{array}$ \\
\hline
\end{tabular}


Three $(21 \%)$ out of the fourteen participants do not hold teaching certificates or teaching licenses, though one of these three is a teacher in a community college. Ten (71\%) of the participants hold current Oregon teaching licenses, and, in addition, two of the Oregon license holders have additional licensure, one in Alaska and one in California. One half $(50 \%)$ of the total $(n=14)$ participants hold middle school teaching certificates. A total of eight participants (57\%) of participants hold elementary education teaching certificates, and four of these participants hold both elementary education and middle school certificates. Two $(14 \%)$ of the total $(n=14)$ participants hold secondary teaching certificates. The types of endorsements participants hold are varied. Table A.1 in Appendix A and shows the subjects and grade levels of teaching endorsements held by the 14 participants.

Additional demographics and background items collected in the pre-workshop questionnaire from the 14 participants included: (a) years teaching environmental education subjects (Item 6); (b) grades taught in the past (Item 7); (c) grades currently teaching (Item 8); (d) type of educational facility where participant teaches (Item 9); (e) environmental education coursework taken in college (Item 11); and, (f) if participant had previously attended any environmental education professional development events (Item 12). Figure A.1 in Appendix A shows the frequency of participants' responses for type of facility where participants teach. Table A.2 in Appendix A shows frequencies of participants' responses to the pre-workshop questionnaire's background items 11 and 12. 
Of the 14 participants, nine attended two or more environmental education professional development (EEPD) events. One of the participants had attended only one EEPD event, and four had not attended any EEPD events at all before their Creeks and Kids Workshop experience. One of the 2009 Creeks and Kids Workshop participants had also attended the 2008 Creeks and Kids Workshop, the participant's only EEPD experience prior to this study.

\section{Instruments}

In order to capture this data, the researcher developed a pre- post-workshop questionnaire design that included quantitative self-reported measures (Appendix D). This instrument was developed to measure the expected outcomes for the Creeks and Kids Workshop in terms of knowledge and skills of participants as well as any change in participants' confidence in their ability to implement knowledge and skills learned during the Workshop. The expected outcomes measured are listed in Appendix B under the subheading “Objectives and Expected Outcomes”. The instrument was a Likertstyle survey that had 67 items across four categories: (1) knowledge of watershed education concepts (with 5 additional open-ended questions); (2) affect toward environmental education and watershed stewardship; (3) confidence in ability to implement inquiry-based watershed education curriculum and field study; and, (4) intent to implement inquiry-based teaching practices and engage learners in environmental education curriculum based on their experience at the Creeks and Kids Workshop. 
The workshop curriculum draws from three sources: The Stream Scene, an active learning guide developed by the Oregon Department of Fish and Wildlife that emphasizes hands-on learning to gain knowledge about watersheds; Project WET, a guide for educators by educators on watersheds and water issues; and, Project WILD Aquatic, an interdisciplinary conservation and environmental education program with a focus on wildlife. All three curricula focus on water and watersheds and provide a large selection of relevant and meaningful environmental education content for educators and students to connect them to their local watershed.

The researcher developed the pre- post-workshop questionnaire to address the knowledge outcomes and teaching methods connected to the activities in the three curricula sources that participants would experience during the 2009 Creeks and Kids Workshop. Specifically, knowledge variables and teaching practices variables were taken directly from the Project WET, Project WILD Aquatic and the Stream Scene curricula. Open-ended knowledge questions (items 22-23) were drawn from the definitions, background and objectives of the Project WET curriculum activities “Capture, Store, and Release”, "Branching Out!”, "Get the Ground Water Picture”, “Amaze-ing Water", and "Sum of the Parts" (Project WET, 1995).

Affect, intent to act and additional knowledge variables of the pre- postworkshop questionnaire were developed by the researcher based on the clear goals and objectives laid out in the grant proposal (Appendix F) written by the Creeks and Kids Workshop leader to the Oregon Department of Fish and Wildlife Restoration and Enhancement for the purpose of funding the workshop. In general, the researcher took 
the liberty of constructing questions, using some exact parts of the three curricula previously mentioned and the grant proposal when available to get questions and statements as close to the learning objectives as possible.

A follow-up form was distributed via email to willing participants in the late winter and early spring of 2010. The follow-up form had nine questions created by the researcher to uncover how participants chose to implement and/or share Creeks and Kids curriculum and instruction within and outside of their educational settings. These questions were not based on any objectives or information from the three curricula used in the Creeks and Kids Workshop. A copy of the follow-up form can be found in Appendix E.

An observation protocol was developed by the researcher to follow during field notes and observations of participants. An interview protocol was also developed for the semi-structured teacher-participant interviews. Both protocols are in Appendix C. These protocols were checked for clarity and content by an experienced field researcher from the Center for Science Education at Portland State University. The protocol included an outline of the format to describe the interaction or observation and how to write up reflective notes.

Face validity was used to establish a measure of validity for the pre- postworkshop questionnaire. Face validity aims to establish if the operationalization seems like a good translation of the construct (Trochim, 2007). Trochim (2007) explains that, "any time you translate a concept or construct into a functioning and operating reality 
(the operationalization); you need to be concerned about how well you did the translation." The pre- post-workshop questionnaire used to measure quantitative data for the Creeks and Kids case study aimed to assess the face validity of knowledge, affect, confidence and intent-to-act measures.

To establish face validity, the pre- post-workshop questionnaire was sent to a carefully selected sample of education experts within Portland State University's Center for Science Education who are familiar with researching and testing educators for knowledge, skill, affect and intent-to-act in various educational settings (K-12 classrooms, environmental education centers). These experts reported with the judgment that the researcher's pre- post-workshop questionnaire measures appeared to be a good measures of knowledge, affect, confidence and intent-to-act (Trochim, 2007).

The instrument was also sent to the Teacher Education Specialist (TES) who coordinates and implements all aspects of the Creeks and Kids curricula, including the goals and objectives that workshop participants should understand and be able to implement post-workshop in their respective educational settings. The TES reported back to the researcher that the instrument appeared to be a good measure of the goals of the Creeks and Kids Workshop and the objectives that participants were supposed to meet and feel comfortable with after attending the workshop.

The instrument developed for this study was then piloted with four educators who were not involved with the Creeks and Kids Workshop in order to correct for any questions or statements that were unclear. After this initial piloting phase and minor 
wording changes to the instrument, the pre-workshop questionnaire was delivered to 14 Creeks and Kids Workshop participants before the July 20, 2009 start date of the workshop.

\section{Procedure}

Pre-workshop questionnaires were emailed or mailed to teacher-participants in early June 2009. All 14 pre-workshop questionnaires were returned to the researcher on or before the July 20, 2009 due date at the start of the Creeks and Kids Workshop. A total of 14 pre-workshop questionnaires were originally sent out and completed, but one questionnaire was rendered unusable and therefore had to be disqualified from the preworkshop questionnaire data set, decreasing the number of usable questionnaires to 13 total. These questionnaires intended to measure the expected outcomes listed in Appendix B under the subheading "Objectives and Expected Outcomes” from pre- to post-workshop.

The Creeks and Kids Workshop occurred from July 20, 2009 to July 24, 2009 at Lake Creek Camp in eastern Oregon's Strawberry Wilderness area of Malheur National Forest. During the Creeks and Kids Workshop, the researcher took ongoing notes by hand in a field journal while observing participants and workshop instructors. Informal conversations with participants also added to the researcher's notes and qualitative data collection. The researcher developed all interview and field observation protocols that were adhered to during data collection. These protocols are in Appendix C. 
Post-workshop questionnaires were mailed and emailed to the 13 participants who took the pre-workshop questionnaire starting two weeks after the end of the Creeks and Kids Workshop. The post-workshop questions mirrored those of the pre-workshop.

The researcher performed post-workshop interviews with available participants to gain further insight into the type of experiences participants had and to reveal any similar or dissimilar patterns related to the quantitative data. Four out of the 14 participants were available for a post-workshop interview. Three of the interviews were telephone interviews and one interview was face-to-face between the participant and the researcher.

During the interviews, the researcher typed exact answers and additional notes using a computer. The interview asked participants 10 questions about their motivation to participate in the Creeks and Kids Workshop and their experiences that resulted from being a participant. The interview questions were semi-structured to solicit the same set of information from all respondents while allowing room to explore additional thoughts or issues that emerged during the interview that respondents felt important to include.

The subjects and variables explored in the interviews were:

a) Primary motivations for attending the Workshop

b) Aspects of the Workshop that were most satisfying

c) Aspects most challenging or frustrating

d) Any anticipated outcomes from participation in Workshop

e) If participation in the Workshop encouraged reflection on current teaching strategies and approaches to science inquiry and environmental education 
f) If any Workshop topics caused anxiety or uncertainty based on participants' previous knowledge, skill level or experience with the topics

g) If participant anticipates that their teaching approaches/strategies will change as a result of participation in the Workshop

h) If participant will share his or her experience with colleagues

i) The participants' sense of the approachability, professionalism, and teaching abilities of the Creeks and Kids Workshop staff, and if any instructors stood out and why

j) Any additional thoughts and comments

Four instructors from the Creeks and Kids Workshop were interviewed over the phone after the Workshop had ended. The researcher typed exact answers and additional notes using a computer during the interviews. Interview questions with instructors were semi-structured with open-ended questions to allow instructors to tell the story of how they came to become involved with the Creeks and Kids Workshop, their teaching styles and methods to assess learning, thoughts on models of professional development and how they feel about being involved in the workshop. There were no scoring rubrics used for participant or instructor interview data.

Qualitative items on the questionnaire, interviews, and field and observation notes were analyzed by coding recurring ideas, words and phrases into themes and categories. Some data was left intact as full quotes and was not part of the coding process. The qualitative data analysis model created by Connolly was applied to the open-ended knowledge questions on the pre- post-workshop questionnaire (items 2226), field notes, and interview data. Qualitative analysis methodology was adapted from 
the Connolly model that involves an initial phase to conduct analysis of the data sentence-by-sentence and word-by-word for recurring words and phrases. Lists of meaning and coded notes from the initial phase were used to develop themes from the coded notes (Connolly, 2003, as cited in Austin et. al, 2009). The themes were translated into conceptual categories, thus, the process involved movement from data to themes and from themes to conceptual categories to provide connections among the themes. This process of coding data in this way to construct meaning and make interpretation about meaning is also supported by the work of Esterberg (2002), Jackson (2003) and Creswell (2008).

For the quantitative data on the questionnaire, t-test statistical analysis was used to compare mean scores of participants within and across categories of: (1) knowledge (items 27-47); (2) affect (items 17-21, 54, 56-58, 61, 62,64); (3) confidence (items 63, 65-67); and (4) intent to act (items 48-53) (Appendix D). All statistical procedures were carried out with the available data analysis functions in Microsoft Excel. Due to the small sample size $(n=13)$ of this case study, the t-test statistic was deemed the best method of quantitative item analysis.

Threats to external validity for this case study include interaction of selection and treatment and interaction of setting and treatment (Creswell, 2008). The interaction of selection and treatment threat is present since the population sample for this study does not permit the results of the research to be generalized beyond the study group to any larger populations. The interaction of setting and treatment threat to external validity exists due to the inability for the research findings to be generalized from the 
setting where this study took place at Lake Creek Camp to other settings, outdoors or otherwise (Creswell, 2008).

Threats to internal validity that are related to research participants include history and selection (Creswell 2008). The time that passed from when participants took the pre-workshop questionnaire to when they completed the post-workshop questionnaire varied anywhere from one month to three months. Since it was not possible to ensure that all participants would complete the post-workshop questionnaire at exactly the same time and return it to the researcher, history became a threat to the internal validity of the study. Selection is also a threat to the internal validity of this study as the population sample was a self-selected convenience sample of Creeks and Kids Workshop attendees who volunteered to participate in the study. There were many similarities between the 14 educator-participants, including that 13 were female and that all 14 had higher education degrees. Random sampling to address this threat to internal validity was not available to the researcher during this study. 


\section{Chapter IV: Results}

Results are organized into five sections: 1) qualitative results from teacherparticipant interviews; 2) qualitative results from instructor interviews; 3) quantitative results from pre and post-workshop questionnaires; and 4) qualitative and quantitative results from teacher-participant follow-up forms; and, 5) observations and comments from the researcher as a participant-observer. To frame the results and give the reader a context of the proceedings of the Creeks and Kids workshop, a detailed description of the setup and format of the workshop can be found in Appendix B.

\section{Section 1: Qualitative Results from Teacher-participant Interviews}

The purpose of this section of results is to report the qualitative data that resulted from the in person and over the phone interviews of workshop participants who elected to be interviewed. Specifically, section 1 includes the qualitative information collected from questions 1-9 on the teacher-participant interview form (Appendix D). The purpose of this analysis of data is to gather information on the participants' experiences from the workshop that a Likert number cannot fully capture. Through interviews, participants can explain in further detail their experience during and after the Creeks and Kids Workshop, and comment on any perceived changes in knowledge, affect, confidence and intent to implement what they learned. In addition, participants' answers were analyzed to reveal any connections to the National Research Council's (NRC) Standards for Professional Development of Teachers of Science (NRC, 1996) as listed 
in the Literature Review. Numbers after quotes, such as (007), are numbers to substitute names of teacher-participants to ensure confidentiality. The results correspond to the original list of responses that can be found in Appendix D.

What were your primary motivations for attending the Creeks and Kids Workshop? (Q\#1)

Table 4.1 shows the coding results of responses to the question on teacherparticipants' motivations to attend Creeks and Kids.

Table 4.1: Coded responses for Q\#1 "What were your primary motivations for attending the Creeks and Kids Workshop" $(\mathrm{n}=4)$

\begin{tabular}{|c|c|}
\hline Words and phrases identified & Initial Theme(s) \\
\hline $\begin{array}{ll}\text { - } & \text { Ways to adapt EE to curriculum* } \\
\text { - } & \text { Learn different ways to present } \\
\text { materials } \\
\text { - } & \text { Get away from lecture-style } \\
\text { - } & \text { Different ways of delivery }\end{array}$ & $\begin{array}{ll}\text { - } & \text { Curriculum delivery } \\
\text { - } & \text { Change in teaching practices } \\
\text { - } & \text { Intent to modify teaching } \\
\text { methods } \\
\text { - } \\
\text { Intent to make a change in } \\
\text { teaching practice }\end{array}$ \\
\hline $\begin{array}{ll}\text { - } & \text { Fun } \\
\text { - } & \text { Fun and interesting }\end{array}$ & $\begin{array}{l}\text { - Have an enjoyable } \\
\text { professional development } \\
\text { experience }\end{array}$ \\
\hline
\end{tabular}

*EE is the abbreviation for Environmental Education.

Direct quotes from teacher-participants included:

- 'I've been thinking of ways to adapt environmental education aspects to a new grade level curriculum, and this workshop seemed to align with my current curriculum goals.” (009).

- "I was referred to Creeks and Kids during a class at Portland State, and I wanted to become more comfortable with doing inquiry lessons with students outside." (012). 
- "I wanted to get away from a lecture-style way of teaching and learn different ways of presenting material to students." (011).

The responses for Q\#1 from telephone interviews revealed the main motivations of teacher-participants for attending the Creeks and Kids workshop: (1) intent to learn new teaching practices and methods of curriculum delivery; (2) to have an enjoyable and fun experience while at the workshop; and, (3) the affordability of the workshop due to its low cost. These results reflect the criteria of Professional Development Standards A-C regarding the need to experience hands-on and inquiry-driven learning methods in order to adopt such strategies in one's own approach to teaching.

What aspects of the workshop were most satisfying? (Q\#2)

Table 4.2 gives a detailed outline of themes coded from words and phrases provided by results from $\mathrm{Q} \# 2$ of the telephone interview. These results directly connect to Professional Development Standard A that states that science learning experiences for teachers should address issues, events, problems or topics significant in science and of interest to participants (NRC, 1996). 
Table 4.2: Coded Responses for Q\#2 “Aspects of the workshop that were most satisfying” $(n=4)$

\begin{tabular}{|c|c|}
\hline $\begin{array}{c}\text { Words and phrases } \\
\text { identified }\end{array}$ & Initial Theme(s) \\
\hline $\begin{array}{ll}\text { - } & \text { Hands-on } \\
\text { - } & \text { Actually doing activities }\end{array}$ & $\begin{array}{ll}\text { - } & \text { Learning by doing } \\
- & \text { Learning through inquiry } \\
\text { - } & \text { Different approach to learning }\end{array}$ \\
\hline $\begin{array}{ll}\text { - } & \text { Practical ways to do activities } \\
\text { - } & \text { Good demonstration of activities } \\
\text { - } & \text { Doing activities } \\
\text { - } & \text { Activities feasible to do with } \\
\text { students }\end{array}$ & $\begin{array}{ll}- & \text { Good modeling } \\
- & \text { Modeling of teaching approach/practices } \\
- & \text { Learning through good modeling of } \\
& \text { practice } \\
-\quad & \text { Modeling demonstrates classroom } \\
\text { application }\end{array}$ \\
\hline $\begin{array}{ll}\text { - } & \text { Fieldwork } \\
\text { - } & \text { Being outside } \\
\text { - } & \text { Being in creek/water } \\
\text { - } & \text { Doing activities outside } \\
\text { - Seeing field setup excellent }\end{array}$ & $\begin{array}{ll}\text { - } & \text { Fieldwork is important } \\
\text { - } & \text { Fieldwork is enjoyable } \\
& \text { experiencing fieldwork important and } \\
& \text { enjoyable }\end{array}$ \\
\hline $\begin{array}{l}\text { - Love water activities } \\
\text { - } \\
\text { - } \\
\text { Foing field activities comfortable to bring kids } \\
\text { - } \text { to water } \\
\text { - } \\
\text { - Fieldwork } \\
\text { - } \\
\text { invertebrates activities great } \\
\text { Love being in water }\end{array}$ & $\begin{array}{ll}\text { - } & \text { Connection to water activities } \\
\text { - } & \text { Water activities enjoyable } \\
\text { - } & \text { Field activities enjoyable } \\
\text { - } & \text { Doing outdoor activities lends teachers } \\
& \text { confidence to do them with students }\end{array}$ \\
\hline $\begin{array}{l}\text { - Challenges made me think of how } \\
\text { to approach challenges in a } \\
\text { classroom } \\
\text { - That it's normal and OK to be } \\
\text { frustrated }\end{array}$ & $\begin{array}{l}\text { - } \\
\text { - Weeling comfortable with challenge } \\
\text { participants embrace challenge } \\
\text { - Workshop experience inspired } \\
\text { participants to gain new perspective on } \\
\text { classroom challenges }\end{array}$ \\
\hline
\end{tabular}

Direct quotes from participants included:

- "I love that workshop!" (003).

- "They gave us practical ways to instantly integrate into the classroom without having to stretch" (009).

- "The field activities and setup was extraordinary" (012).

- "Getting comfortable to bring kids to the water!" (012).

- "I loved the water activities" (009). 
- "I love being in the water" (013).

Aspects of the Creeks and Kids Workshop that participants indicated as the most satisfying included: (a) learning through inquiry; (b) learning through good modeling and practices (by instructors and other participants); (c) the importance and enjoyment of inquiry and fieldwork; (d) how fieldwork boosted the comfort levels of participants to do lessons and activities with students; and, (e) how the workshop experience helped participants embrace challenge. The direct quotes offer evidence that participants had a positive overall experience during the workshop. The results on the effective modeling of teaching practices and the opportunities for a variety of fieldwork options connect to criteria in Professional Development Standard B. This criterion indicates that learning experiences for teachers should occur in a variety of places where effective science teaching can be illustrated and modeled, permitting teachers to struggle with real situations and expand their knowledge and skills in appropriate contexts (NRC, 1996).

What aspects of the workshop were challenging and/or frustrating? ( $Q \# 3)$

Table 4.3 shows responses surrounding group dynamics, lack of engagement of group members, and difficulty working with peers. 
Table 4.3: Coded Responses for Q\#3 "What aspects of the workshop were challenging and/or frustrating?" $(\mathrm{n}=4)$

\begin{tabular}{|c|c|}
\hline Words and phrases identified & Initial Theme(s) \\
\hline $\begin{array}{ll} & \text { Group activities with peers } \\
\text { - } & \text { Dealing with group personalities } \\
\text { - } & \text { difficulty engaging with group } \\
\text { members } & \text { Group personalities } \\
\text { - } & \text { Working with fellow teachers } \\
\text { - } & \text { Got frustrated in activities and } \\
\text { groups } & \text { Recognized potential frustration } \\
\text { of students }\end{array}$ & $\begin{array}{ll} & \text { Group dynamics } \\
\text { - } & \text { Difficulty working with peers } \\
\text { - } & \text { Group engagement levels } \\
\text { - } & \text { Group dynamics offer new } \\
& \text { perspectives in the classroom }\end{array}$ \\
\hline $\begin{array}{l}\text { - Need more activity modification } \\
\text { for primary/elementary audience } \\
\text { - More field activities, less indoor } \\
\text { classroom time }\end{array}$ & $\begin{array}{l}\text { - } \quad \text { Areas for improvement in Workshop } \\
\text { - Workshop delivery needs to be } \\
\text { modified for broader grade } \\
\text { levels/audiences }\end{array}$ \\
\hline
\end{tabular}

The most challenging aspect of for participants was the task of working with their peers. Though some respondents agreed that working with their peers was difficult, others $(007,013)$ revealed that the challenge they experienced helped them gain a new perspective on the group dynamics of students who work together in the classroom. These results directly connect to Professional Development Standard A that states that professional development opportunities for science teachers should encourage and support teachers in efforts to collaborate (NRC, 1996).

Direct quotes from teacher-participants that expand upon this theme include:

- 'It made me realize that students won't always work (collaboratively) together, but the end result seems to make it very worth it, even if it's challenging" (007).

- "The frustration and challenge of working with group members made me realize the benefit of having students work together in groups in order to help prepare them for the realities of the workplace" (013). 
- "It was difficult having to react and deal with different personalities instead of working on activities" (008).

- "When frustration came up, I realized it's OK to be frustrated and challenged" (009).

Additional statements revealed frustrations unrelated to working with peers:

- "It seemed like the crux of the workshop was geared towards middle to high school; should be more modifications for primary" (008).

- "There should be more field activities, less classroom time" (002).

In summary, most participants perceived that group work might have the potential to foster new perspectives on and tolerance for peer collaboration. Participants also recognized the benefit to of having students perform group work in the classroom from their own experiences with peers. In total, participants did not have a lot of negative comments about the workshop itself, save for the desire for more field study and that improvement could be made in tailoring the workshop to primary and elementary teachers' needs.

Did you have any anticipated outcomes before attending the workshop? (Q\#4)

Only two participants offered responses different from an answer of "no" to this question. One participant mentioned that s/he did not originally know what a watershed was, so had no expectations prior to attending Creeks and Kids. Another respondent 
replied that because it is very difficult to get a professional development workshop with a field experience, expectations were high.

What actual outcomes did you perceive after attending the workshop? (Q\#5)

Interview Q\#5 asked participants to identify any perceived outcomes that resulted from their participation in the Creeks and Kids Workshop. Table 4.4 displays coded responses revealing participants' perceived outcomes from attending the Creeks and Kids workshop.

Table 4.4: Coded Responses for Q\#5 “Anticipated outcomes from attending the Workshop" $(n=4)$

\begin{tabular}{|c|c|}
\hline Words and phrases identified & Initial Theme(s) \\
\hline $\begin{array}{ll}\text { - } & \text { Energized } \\
\text { - } & \text { Enthusiastic } \\
\text { - } & \text { Expectation exceeded } \\
\text { - } & \text { Take away exceeded expectations } \\
\text { - } & \text { Inspirational, start environmental } \\
& \text { afterschool club } \\
\end{array}$ & $\begin{array}{ll}\text { - } & \text { Workshop exceeded participant } \\
\text { expectations } \\
\text { - Workshop inspired energy and } \\
\text { enthusiasm to teach curriculum } \\
\text { - Workshop inspires extracurricular } \\
\text { activities }\end{array}$ \\
\hline $\begin{array}{l}\text { - Water is engaging } \\
\text { - Water complements any curriculum } \\
\text { - Water theme to meet benchmarks } \\
\text { - Water theme supports to help } \\
\text { students put EE into action* }\end{array}$ & 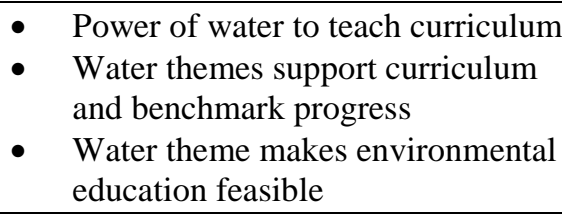 \\
\hline
\end{tabular}

*EE is the abbreviation for Environmental Education.

Direct quotes from responses to Q\#5 include:

- "Water is a great theme to put environmental education into action" (007).

- "It definitely helped me to feel more comfortable about how to have students put environmental education into action" (007).

- “I'm now energized and excited to teach kids about what I've learned!" (012).

- "All of my expectations were met and exceeded" (009).

- "I took away so much more than I expected" (008). 
- "It inspired me to start an afterschool club to focus just on environmental issues" (012).

Participants agreed that using water as an integrated theme for teaching across disciplines is engaging for students and that water education complements any curriculum. It appears that some teacher-participants also believe that the theme of water can integrate cross-curricular concepts to help them to meet benchmarks. Participants left the experience with new ideas and enthusiasm to apply what they learned during the workshop with their students. These results address the criteria of Professional Development Standard D of how programs like Creeks and Kids should recognize the history, culture and organization of the school environment so that teachers can directly implement what is learned in a professional development program. These results also connect to Professional Development Standard A, which states that science learning experiences for teachers should address issues, events, problems or topics significant in science and of interest to participants (NRC, 1996).

Did Creeks and Kids encourage you to reflect on current teaching strategies or approaches to environmental education and/or science education? (Q\#6)

Results revealed that some participants' current teaching practices were reaffirmed, as some already use hands-on curriculum and inquiry in their classrooms. A few participants had these statements to offer: 
- "I used to think that I had to stick strictly to the textbook. I now know that I can bring environmental education into the classroom and still teach to the curriculum" (012).

- "In addition to showing us practical applications, I realized that teachers teaching teachers is important" (009).

- "The graduate credit assignment that forced me to sit down and reflect right away was valuable, I had to figure out how I would apply the lessons and activities I learned (during the workshop)" (013).

Teachers who attended Creeks and Kids for graduate credit completed a reflection assignment that asked them to create a classroom implementation plan for activities and lessons they learned during the workshop. This task directly connects to Professional Development Standard C that states that professional development for teachers of science should provide opportunities for them to learn and use various tools and techniques for self-reflection and collegial reflection, such as peer coaching, portfolios and journals (NRC, 1996). Participant responses reflect that their own thinking about how to apply what they learned became an important piece of the workshop, and that this was aided by their collaboration with other teacher-participants during the workshop. These results also reflect the criteria for collaboration as mentioned in Professional Development Standard A. 
Were there any workshop topics that caused you anxiety or uncertainty? (Q\#7)

All but two participants answered this question with a "no", indicating that they had not experienced anxiety during the workshop. One participant commented that the group activity at the end of the workshop culminating in a final presentation gave him/her a feeling of uncertainty, but that it ultimately helped him/her learn more about group dynamics. The other participant revealed that $\mathrm{s} /$ he had anxiety prior to the workshop because s/he did not know what a watershed was. A direct quote from this participant explains further:

- 'I didn't even know what a watershed was, but on the first day (of the workshop) when we drove up to the vista point to see the watershed it made things clear for me" (010).

Overall, responses did not reveal any patterns of anxiety or uncertainty among the teacher-participants during or after the Creeks and Kids workshop.

Did you share your Creeks and Kids experience with any of your colleagues? (Q\#8)

Teacher-participant responses revealed the ways they shared their opinions and what they learned during the Creeks and Kids workshop within and outside of their education settings. Table 4.5 displays results coded from participant comments. 
Table 4.5: Summary of coded responses for Q\#8 "Did you share your Creeks \& Kids experience with any colleagues?" $(\mathrm{n}=4)$

\begin{tabular}{|l|ll|}
\hline \multicolumn{2}{|c|}{ Words and phrases identified } & \multicolumn{1}{c|}{ Initial Theme(s) } \\
\hline - Shared books & $\bullet$ & Collaboration within and outside of \\
- Recruit teaching partners & & school \\
- Emailed school about how & - Spreading enthusiasm \\
- Sonderful (workshop) was & - Treating teachers as a team \\
\hline
\end{tabular}

Direct quotes from teacher-participants reveal further insight:

- "Can't wait to get the DVD to talk it up and get more people to go next year!'”(009)

- "I emailed the whole school to tell them it was wonderful!" (012).

- 'I'm trying to get my teaching partner, who I do World Water Monitoring Day with, to go next year" (007).

These results also tie to Professional Development Standard A, stating that science learning experiences for teachers should encourage and support efforts to collaborate with other teachers (NRC, 1996). Responses from the teacher-participants reveal patterns of enthusiasm and an eagerness to share what they learned during the workshop with colleagues shortly after the workshop occurred. Some indicated that they would like to return to participate in the workshop again with colleagues from their schools. 
What was your perception of the Creeks and Kids instructor team? (Q\#9)

Direct quotes from teacher-participants best capture the data regarding their perceptions of the instructors during the workshop:

- "They were absolutely wonderful, all of them" (001).

- "They were all amazing and each one knew their subject really well" (012).

- "I really enjoyed how they left me to my own inquiry but were also supportive by giving a lot of positive reinforcement" (013).

- "I could particularly relate to the instructor who is a classroom teacher and showed us how to easily integrate the curriculum. It helped me understand how to use the theme of water for a lesson, a unit or an entire school year" (002).

- "Their excitement level is what I aspire to be when I teach every class" (012).

- "They had good ideas and helpful teaching strategies to offer" (008).

- "Great classroom management and outdoor field study techniques-I especially like 'Deer Ears' and 'Owl Eyes'”' (001).

The results from responses to this question reveal that the teacher-participants had overall positive opinions of the instructor team. There were no comments of complaint or negativity from any participant. Participants' statements remark on the high quality of instruction and modeling of teaching strategies by the Creeks and Kids instructor team. These results also connect to Professional Development Standard B that highlights how learning experiences for teachers of science should use inquiry, reflection, interpretation of research, modeling, and guided practice to build understanding and skill in science teaching (NRC, 1996). 
Is there anything else you would like to add? (Q\#10)

The last question from the interviews with teacher-participants simply asked for any additional thoughts or comments regarding their Creeks and Kids experience:

- "This workshop is special because of its uniqueness: a lot of workshops talk about hands-on while you're sitting in a seat and taking notes. At Creeks and Kids we were out there doing it." (008).

- "I have more confidence to use the curriculum. I love using the hands-on approach, so that's not new, but the networking with other teachers was great." (004).

- I always thought it (environmental education) was important, but what I taught was limited to my comfort level. The workshop raised my comfort level not only through direct experience with those in the field, but by hearing testimonials of fellow teachers who talked about how they implemented the activities" (009).

- "Without Creeks and Kids, I would never have had the confidence to start an environmental after-school club. Through the teachings of the wonderful adult leaders at Creeks and Kids, I gathered enough of a base understanding of watersheds to further seek out how mine works. From there I felt empowered to contact my local watershed council and request projects for my students" (012).

- "By taking the workshop in such an in-depth manner, I gained the confidence to actually implement the materials. I have been sitting on Project WET and Project WILD Aquatic since 1989 and have rarely broken open the books. Now they are a regular part of what I teach." (009, Follow-up form).

- "Creeks and Kids activities (have been) helping my students gain an understanding of their responsibility to be stewards of the habitat around them" (014). 
These quotes give insight into the confidence some teachers gained to adapt and implement curriculum because of their participation in the workshop. These results tie to Professional Development Standard B that states how professional development experiences should address teachers' needs as learners and build on their current knowledge of science content, teaching, and learning (NRC, 1996). Teachers felt better equipped to use resources outside of the classroom and incorporate extracurricular learning opportunities for students. Participants valued the contact they had with other teachers and hearing the stories others had regarding implementation, practice and challenges.

A summary of this section reveals that participants felt their needs as learners were addressed since the staff of Creeks and Kids provided great modeling of how to teach the material. The Creeks and Kids instructors also continually encouraged teacher-participants to collaborate with one another. During activities and lessons, the staff checked for understanding of outcomes yet allowed time for teacher-participants to experience inquiry learning. Some participants' current teaching practices were reaffirmed, as some already use hands-on curriculum and inquiry in their classrooms, yet others indicated that their perceptions about their ability to implement strategies other than teaching strictly from the textbook had changed. Qualitative interview results indicate that various criteria of the Professional Development Standards A -C of the National Research Council were met during the Creeks and Kids Workshop. 


\section{Section 2: Qualitative Results from Instructor Interviews}

To gain an in-depth look at the workshop from the perspective of the instruction team, interviews of four Creeks and Kids instructors were performed over the phone. Instructors' answers were also analyzed to reveal any connections to the National Research Council's (NRC) Standards for Professional Development of Teachers of Science (NRC, 1996) as listed in the Literature Review. The interview questions were semi-structured with open-ended questions (Appendix D). The responses given by instructors during interviews were separated into themes in order to clearly show the main points about the Creeks and Kids Workshop instructors felt pertinent to include. Numbers such as (004) are substitute for the names of the instructors to ensure confidentiality. A brief background of the instructors is in Appendix A.

Why instructors like teaching at the Creeks and Kids workshop Responses from some instructors are as follows:

- "The transformation I see every time I go is absolutely amazing, that the people there are leading the minds of (students) in the classroom and get inspired to have them learn in a different way" (004).

- "For me, it's easy to put into words: I come back every year to be with the staff because they're great to be around. I love teaching using water as a thematic unit and getting that idea out to teachers. The selfish reason I go is that I learn from all participants-I am always picking up ideas from them" (002). 
- 'I can't imagine my year without it! The participants have so many ideas, it's really inspiring for me, and it's really a week of personal enrichment for me" (001).

The instructors not only get excited to teach at the Creeks and Kids workshop, they also enjoy it as a learning experience. The instructors recognize that collaboration between both the staff and the teacher-participants is important for the success of the workshop. These results also connect to Professional Development Standard A that indicates how professional development experiences for teachers of science should encourage and support teachers in efforts to collaborate (NRC, 1996). The instruction team models collaboration and, in turn, passes this method on to the teacher-participants of the Creeks and Kids Workshop. Overall, instructors are eager to share their own enthusiasm for teaching about water in order to share it with workshop attendees.

What instructors want teacher-participants to gain from the workshop

Each instructor had something to add about the workshop's purpose and goals:

- "My purpose and the whole workshop's purpose is to inspire and empower people who attend so that they feel comfortable taking kids outside. In my mind the whole time I aim to model that behavior and excitement...some people are comfortable with environmental education and some do not know where to start. If you don't have the selfconfidence, you don't know how to share (information), so the workshop is about everyone finding their own level and own way" (001). 
- “The Creeks and Kids Workshop's goal is for teachers to leave there with the confidence and skills to use stream and riparian areas as learning (opportunities)." (003).

- "The main goal is to make the best out of every moment in the stream and classroom situation - make it golden so that people are invested in the outcomes." (004).

Though instructors mentioned the broader goal of bringing an awareness and appreciation of watershed systems to participants, each one emphasized the importance of empowering participants to feel comfortable to teach about water and to teach in the field. These results, especially reflected in the first bullet point above, directly connect to Professional Development Standard A that indicates how science learning experiences for teachers should build on the teacher's current science understanding, ability, and attitudes (NRC, 1996).

How to you assess teacher-participant understanding? What assessment methods do you use as an instructor?

Direct quotes summarize instructors' views on the instructor team's assessment approach:

- "We are always watching to see who is looking lost like a deer in headlights, and (immediately ask) 'what can we do to get them to feel more comfortable?"' (001).

- "We monitor everyone who comes. We meet every night and talk about anyone who might not seem like (he or she) is gaining confidence. We assess by their behavior-if they're talking in groups, reluctant to come forward, whether they want to get involved in stream work - and (the workshop leader) keeps in 
contact with all of them so that they can come back with questions and get assistance, we are all open to being contacted throughout the school year" (003).

The instructors work as a team to make sure that each teacher-participant is comfortable — both with the material taught and with the workshop experience as a whole. Each instructor wants participants and their students to succeed, so they use the best methods possible to allow teachers to leave the workshop with the skills and confidence they need to implement the curriculum and instruction modeled in the workshop. They offer a continuous network of support so that teacher-participants know that this support does not end just because the workshop ends.

Many of the assessment and instructional methods the Creeks and Kids staff uses during the workshop tie to the criteria of Professional Development Standard B that states that professional development for teachers should use inquiry, reflection, interpretation of research, modeling and guided practice to build understanding and skill in science teaching (NRC, 1996). The formative and summative assessment methods the Creeks and Kids instructors use for teacher-participants also connects to points in Professional Development Standard D. Part of Standard D states that quality preservice and in-service professional development programs should: a) have continuous program assessment that captures the perspectives of all those involved; b) use a variety of strategies; c) focus on the process and effects of the program; and, d) feed directly into program improvement and evaluation (NRC, 1996). 
Addressing the individual and collective needs of teacher-participants

Instructors had various comments regarding how the workshop should run in order to address the various needs of teachers who attend. The quotes below sample this stream of thought:

- "There is something really powerful about honoring the position of the participants (teachers). We have things we want to show and teach, but there are opportunities for them to grow and explore what they need and give them opportunities to focus. (A workshop needs) a hands on approach and time to immerse, but should be always asking 'what do the participants need' so you can acknowledge this for them and move forward - knowing your audience and offering support for them to grow" (004).

- "We keep teachers really busy (with activities) and show them the relevance right on the spot of how they can use this (Creeks and Kids curriculum) in the classroom so they can say 'hey, I can do this with my kids!'” (003).

The instructors stressed the importance of making the workshop relevant to what teachers experience and need in the classroom. Each instructor mentioned some aspect that related to how dedicated the instructor team is to make the activities and curriculum as practical as possible for the teacher-participants. They model ways that participants can implement material immediately as well as discuss ways to customize curriculum to suit individual classroom needs.

The importance of working as a team

A theme of teamwork threaded throughout all instructors' statements during interviews. 
- "We all look forward to this, and have a lot of respect for each other and for (the workshop leader) as our organizer. We like being together, but we all know that each other's efforts greatly contribute to the experience (for participants). It's a kick - in education we're always running against the wind, so for four days we run with the wind and have like minds and a good time" (003).

Each spoke in some way about how the investment of every instructor is key to what "makes the workshop go" (002). Everyone works as a team because they are a group of people with the same mission who want to keep coming back every year (004).

Working as a team helped the instructors to create a fun and supportive learning environment that addresses the variety of needs of the workshop's teacher-participants. These results also indicate that the instructional practices of the Creeks and Kids staff are in line with the criteria for collaboration as indicated in Professional Development Standard A (NRC, 1996).

Experiences with other programs and how Creeks and Kids is unique:

Some instructors elaborated on their experiences with other workshops, contrasting them with Creeks and Kids to reveal what makes it unique:

- 'I've done other science education workshops, but the big thing that stood out to me when I first attended Creeks and Kids was the amount of practical field time you get. In other workshops you just go and sit all week, but the chance to actually apply what you've been learning and do what you're supposed to do with kids in the field is rare" (002).

- "All workshops should be this way (like Creeks and Kids). What used to frustrate me about other workshops was that they stand in front of the group and lecture. Even in masters teaching graduate programs they tell you not to lecture, 
but $90 \%$ of the time they do not model that way, you hear it all the time but it is not modeled. Creeks and Kids doesn't tell you the best ways to teach, it models them" (002).

- 'Other (non-Creeks and Kids) workshops I've done have been at times that are not possible for many teachers, and they're given no chance to brainstorm during, and then after don't always walk away with great resources and materials. (Creeks and Kids) is like a mini-lottery for teachers who don't seem to be getting much these days" (004).

- 'It's really powerful to work in the learning environment that is set up the way Creeks and Kids is--it's like nothing I've ever experienced before as a teacher or facilitator. It's absolutely amazing the connections that are made, as there's so much information and resources available" (004).

In summary, each instructor mentioned the importance of modeling best teaching practices instead of lecturing about them. The ability for teachers to gain field experience, actively question through guided inquiry and apply what they have learned so that they can do the same with their students is the cornerstone of the Creeks and Kids Workshop, as was told by instructors to be the essence of what makes the workshop unique. These results reflect the criteria of Professional Development Standards A and B. The instructors' qualitative responses provide results that also reflect connections to the criteria of Professional Development Standard D, especially in the list below that supports that Creeks and Kids allows for:

- Integration and coordination of the program components so that understanding and ability can be built over time, reinforced continuously, and practiced in a variety of situations. 
- Options that recognize the developmental nature of teacher professional growth and individual and group interests, as well as the needs of teachers who have varying degrees of experience, professional expertise, and proficiency.

- Collaboration among the people involved in programs, including teachers, teacher educators, teacher unions, scientists, administrators, policy makers, members of professional and scientific organizations, parents, and business people, with clear respect for the perspectives and expertise of each.

\section{Section 3: Quantitative Results from the Pre-workshop and Post-workshop Questionnaires}

The results for the pre- and post-workshop questionnaires are reported here to reveal any evidence of gains across the knowledge, affect, confidence and intent to act categories. T-test analysis using an alpha level of 0.05 compared pre-workshop and post-workshop means for all quantitative variables. P-values $<0.05$ were recorded as statistically significant. In addition, further analysis was performed to reveal if there were any statistically significant differences across categories between teacherparticipants with less than five years of science teaching experience with those who had more than five years of science teaching experience.

This section is organized as follows: a) statistical results from variables in the knowledge category; b) statistical results from variables in the affect category; c) statistical results from variables in the confidence category; and, d) statistical results 
from variables in the intent to act category. A full list of the pre- post-workshop questionnaire variables is in Appendix D.

Is there a statistically significant gain from pre-workshop to post-workshop questionnaire for participants on variables in the knowledge category after participation in the Creeks and Kids Workshop?

The category of items intended to measure a gain in knowledge from preworkshop to post-workshop contained 21 variables of self-reported knowledge on the various topics addressed in the classroom and field study activities from the Stream Scene, Project WET and Project WILD Aquatic curricula. Two open-ended knowledge questions (Item 22, 23) on watersheds (functions of, health indicators) were also analyzed. Item 22 was analyzed for frequency of responses and for knowledge points based on correct answers given on the pre-workshop and post-workshop questionnaires. Item 23 was analyzed for recurring phrases to give an overall picture of common responses.

A t-test for two sample means of knowledge variables (items 27-47), revealed statistically significant values $(\mathrm{p}<0.05)$ for all 21 variables. The complete pre- postworkshop questionnaires with the itemized knowledge variables can be found in Appendix D. These knowledge variables were taken directly from the objectives and outcomes listed in both the Teacher Education Specialist's grant proposal (Appendix B) and from the three curricula used during the workshop (The Stream Scene, Project WET, Project WILD Aquatic). 
Table 4.6 displays the statistical results for knowledge variables 27-47.

Table 4.6: T-test Paired Two Sample for Means Results for Knowledge Items 27-47 $(n=13)$

\begin{tabular}{|c|c|c|c|c|}
\hline Knowledge Variable & $\begin{array}{l}\text { Pre- } \\
\text { Mean }\end{array}$ & $\begin{array}{l}\text { Post- } \\
\text { Mean }\end{array}$ & t-test & p-value \\
\hline Aquatic organisms & 2.69 & 3.85 & -5.20 & $* * *$ \\
\hline Macro-invertebrates & 2.77 & 4 & -4.79 & $* * *$ \\
\hline $\begin{array}{l}\text { Relationships among } \\
\text { precipitation, runoff, and } \\
\text { aquatic habitats }\end{array}$ & 3.69 & 4.38 & -2.92 & 0.01 \\
\hline Salmon Life Cycle & 3.46 & 4.23 & -3.83 & $* * *$ \\
\hline $\begin{array}{c}\text { Human impacts to streams and } \\
\text { watersheds }\end{array}$ & 3.92 & 4.46 & -2.94 & 0.01 \\
\hline $\begin{array}{l}\text { The movement of water within } \\
\text { the water cycle }\end{array}$ & 4.38 & 4.77 & -2.13 & 0.01 \\
\hline $\begin{array}{l}\text { The states of water as it moves } \\
\text { through the water cycle }\end{array}$ & 3.92 & 4.69 & -2.38 & 0.02 \\
\hline $\begin{array}{c}\text { Strategies to assess the health of } \\
\text { a stream }\end{array}$ & 2.77 & 3.92 & -5.20 & $* * *$ \\
\hline Topography & 3 & 4.08 & -4.50 & $* * *$ \\
\hline Wildlife Inventory & 2.62 & 3.31 & -3.96 & $* * *$ \\
\hline Water quality testing & 2.92 & 2.85 & -3.49 & $* * *$ \\
\hline Data collection in the field & 2.92 & 3.92 & -3.34 & $* * *$ \\
\hline $\begin{array}{l}\text { Calculating the area of a field } \\
\text { study site }\end{array}$ & 2.46 & 3.69 & -7.41 & $* * *$ \\
\hline $\begin{array}{l}\text { Calculating the weight of water } \\
\text { falling on a field study site }\end{array}$ & 2 & 3.31 & -4.98 & $* * *$ \\
\hline $\begin{array}{l}\text { Determining specific and } \\
\text { annual rainfall and runoff }\end{array}$ & 1.85 & 2.77 & -3.21 & $* * *$ \\
\hline $\begin{array}{l}\text { Tracing the course of water to } \\
\text { aquatic habitats }\end{array}$ & 2.23 & 3.62 & -3.77 & $* * *$ \\
\hline
\end{tabular}




\begin{tabular}{|c|c|c|c|c|}
\hline Knowledge Variable & $\begin{array}{c}\text { Pre- } \\
\text { Mean }\end{array}$ & $\begin{array}{c}\text { Post- } \\
\text { Mean }\end{array}$ & t-test & p-value \\
\hline Fish identification & 2 & 3.15 & -4.63 & $* * *$ \\
\hline Watershed and stream mapping & 1.85 & 3.77 & -4.63 & $* * *$ \\
\hline Stream surveying & 2.08 & 3.77 & -4.64 & $* * *$ \\
\hline Fish sampling & 1.46 & 3.38 & -8.04 & $* * *$ \\
\hline Fish dissection & 2.15 & 3.54 & -3.32 & $* * *$ \\
\hline
\end{tabular}

***Indicates that p-value was less than 0.001 .

Open-ended knowledge question 22 asked participants to "list 2-3 functions of watersheds." (Appendix D). Each respondent was given one point for every correct answer. Correct answers were drawn from the definitions, background and objectives of the Project WET curriculum activities “Capture, Store, and Release”, “Branching Out!”, "Get the Ground Water Picture", "A-maze-ing Water", and "Sum of the Parts" (Project WET, 1995). All respondents gave the minimum required two correct answers for item 22 in both the pre-workshop and the post-workshop questionnaire. Participants 002, 006, 010 and 014 were the only participants with point gains in knowledge score from pre- to post-workshop questionnaire. Additional analysis revealed no statistically significant findings comparing these teachers among categories of those with less than five years of science teaching experience to those who had more than five years of teaching experience.

Item 23 asked participants to "list 2-3 ways in which you think you can contribute to watershed health and restoration." In order to get a broad picture of ideas that the sample of participants held for this question, responses were analyzed for frequency on the pre/post-workshop questionnaires overall. Table 4.7 shows the results 
for the analysis of recurring words and themes for item 23. The most frequent responses given were: (1) education, with 10 occurrences; (2) volunteer restoration projects for fish, habitat and plant restoration with a total of six occurrences; and (3) plant trees and native plants, with five occurrences. Other responses were given with less frequency, such as to avoid building (hydropower) dams and to purchase food from local and sustainable farms.

Table 4.7: Frequency of recurring words and phrases for item 23 "List 2-3 ways in which you can contribute to watershed health and restoration" $(n=13)$

\begin{tabular}{|l|c|}
\hline \multicolumn{1}{|c|}{ Statement } & Count/Frequency \\
\hline Education & 10 \\
\hline Eliminate use of pesticides/herbicides & 7 \\
\hline $\begin{array}{l}\text { Volunteer restoration projects } \\
\text { (for fish, habitat, plants, stream banks) }\end{array}$ \\
\hline Plant trees and native plants & 5 \\
\hline Reduce use of water & 2 \\
\hline $\begin{array}{l}\text { Bioswales } \\
\text { Recycling }\end{array}$ & 2 \\
\hline $\begin{array}{l}\text { Remove invasive plants species; Avoid building } \\
\text { (hydropower) dams; Reduce consumption of } \\
\text { unsustainable materials }\end{array}$ & 1 (each statement only 1 count) \\
\hline
\end{tabular}


Is there a statistically significant gain from pre-workshop to post-workshop questionnaire for participants on variables in the affect category after participation in the Creeks and Kids Workshop?

This section of the results reports teacher-participants' responses to affect questions on the pre- and post-workshop questionnaires. Out of the 14 variables analyzed, only two variables showed statistically significant results from a t-test analysis of participant responses from pre- to post-workshop questionnaire.

Table 4.8 shows the percentages of responses for questionnaire items 17-21 (Appendix D). A t-test revealed a statistically significant value of $\mathrm{p}=0.04$ for item 18 that asked participants "How important is environmental education to you personally?" Item 19 on the questionnaire asked respondents, "How interested are you in incorporating environmental education into your curriculum?” A t-test revealed a statistically significant $p$-value $=0.001$. There were no further statistically significant results $(\mathrm{p}<0.05)$ from $\mathrm{t}$-tests comparing the remaining affect variables on the questionnaire. 
Table 4.8: Percentage of Responses for Items 17-21 in Affect Category ( $n=13)$

\begin{tabular}{|l|c|c|c|c|}
\hline \multicolumn{1}{|c|}{ Statement } & Moderately & $\begin{array}{c}\text { Considerably } \\
(\%)\end{array}$ & $\begin{array}{c}\text { Extremely } \\
(\%)\end{array}$ \\
\hline $\begin{array}{l}\text { How important is it that } \\
\text { K-12 students have EE in } \\
\text { their curriculum?* }\end{array}$ & Pre- & $0 \%$ & $46 \%$ & $54 \%$ \\
\hline & Post- & $0 \%$ & $38 \%$ & $62 \%$ \\
\hline $\begin{array}{l}\text { How important is EE to } \\
\text { you personally?* }\end{array}$ & Pre- & $8 \%$ & $38 \%$ & $54 \%$ \\
\hline $\begin{array}{l}\text { How interested are you to } \\
\text { incorporate EE into your } \\
\text { curriculum?* }\end{array}$ & Pre- & $23 \%$ & $23 \%$ & $54 \%$ \\
\hline $\begin{array}{l}\text { Post- } \\
\text { How important do you } \\
\text { students or community in } \\
\text { environmental education } \\
\text { service learning? }\end{array}$ & Pre- & $23 \%$ & $31 \%$ & $46 \%$ \\
\hline & Post- & $0 \%$ & $31 \%$ & $69 \%$ \\
\hline $\begin{array}{l}\text { How concerned are you } \\
\text { about the health of } \\
\text { streams and watersheds? }\end{array}$ & Pre- & $8 \%$ & $23 \%$ & $69 \%$ \\
\hline & Post- & $0 \%$ & $23 \%$ & $77 \%$ \\
\hline
\end{tabular}

*EE is the abbreviation for Environmental Education.

Is there a statistically significant gain from pre-test to post-test for participants on variables in the confidence category after participation in the Creeks and Kids Workshop?

This section includes the t-test results of four items from the questionnaire category of responses for teacher-participants' confidence in their ability to understand 
and apply some of the learning outcomes from the Creeks and Kids curricula and the outcomes indicated in the grant proposal written by the Creeks and Kids Teacher Education Specialist (Appendix F).

Table 4.9 indicates the p-value results for items 63, 65-67 (Appendix D) in the confidence category of the pre-test/post-test questionnaire. All items revealed statistically significant results with p-values $<0.05$. Additional analysis revealed no statistically significant findings comparing teachers with less than five years of science teaching experience with those who had more than five years of teaching experience.

Table 4.9: T-test statistical results and p-values for confidence variables from pre/post-workshop questionnaire $(n=13)$

\begin{tabular}{|c|c|c|c|c|}
\hline Confidence Variable & $\begin{array}{c}\text { Pretest } \\
\text { Mean }\end{array}$ & $\begin{array}{l}\text { Posttest } \\
\text { Mean }\end{array}$ & t-test & p-value \\
\hline $\begin{array}{l}\text { I feel qualified to compare watershed } \\
\text { data over time to identify healthy and } \\
\text { sub-healthy watersheds }\end{array}$ & 2.77 & 4.23 & -3.08 & $* * *$ \\
\hline $\begin{array}{l}\text { I feel that I am currently able to } \\
\text { propose } 2-3 \text { strategies to improve the } \\
\text { health of sub-healthy watersheds }\end{array}$ & 3.38 & 4.38 & -2.55 & 0.01 \\
\hline $\begin{array}{l}\text { I feel that I would be able to contribute } \\
\text { as a member of a team to conduct } \\
\text { watershed surveys }\end{array}$ & 3.46 & 4.62 & -2.56 & 0.01 \\
\hline $\begin{array}{l}\text { I am able to discuss the role that } \\
\text { citizens play in watershed stewardship }\end{array}$ & 3.54 & 4.23 & -2.00 & 0.03 \\
\hline
\end{tabular}

***Indicates that $\mathrm{p}$-value was less than 0.001 . 
Is there a statistically significant gain from pre-to post-workshop questionnaire for participants on variables in the intent to act category after participation in the Creeks and Kids Workshop?

Table 4.10 displays the quantitative results from the variables in the intent to act category. A full list of variables from the pre/post-workshop questionnaire can be found in Appendix D. Results from t-test analysis revealing p-values that were $<0.05$ were statistically significant. Additional analysis revealed no statistically significant findings comparing teachers with less than five years of science teaching experience with those who had more than five years of teaching experience.

Table 4.10: $\mathrm{P}$-values from t-test statistical results for items 48-53 intent to act category $(\mathrm{n}=13)$

\begin{tabular}{|l|c|}
\hline \multicolumn{1}{|c|}{ Statement } & P-value from t-test statistical results \\
\hline Encourage the process of scientific inquiry & $* * *$ \\
\hline Engage students in *EE curriculum and activities & 0.02 \\
\hline Let students guide discussions & 0.18 \\
\hline $\begin{array}{l}\text { Allow students to conduct their own experiments } \\
\text { collect data }\end{array}$ & 0.12 \\
\hline Engage students in outdoor *EE lessons & 0.02 \\
\hline
\end{tabular}

*EE is the abbreviation for environmental education. ***Indicates that p-value was less than 0.001 .

Statistically significant p-values of $<0.05$ resulted for the following items: (1) encourage the process of scientific inquiry; (2) engage students in environmental education (EE) curriculum and activities; (3) have students use science equipment or 
tools to collect data; and (4) engage students in outdoor environmental education (EE) lessons. As an additional inquiry revealed, there were no statistically significant findings comparing teachers with less than five years of science teaching experience with those who had more than five years of teaching experience.

The quantitative results from the pre- and post-workshop questionnaires indicated statistical significance across all categories. The knowledge category, though self-reported, revealed that all teacher-participants showed a gain in knowledge variable from pre- to post-workshop questionnaire. This was also true in the confidence category, the category that most directly connects to the official outcomes that the Creeks and Kids Workshop director and staff deem a participant should experience as a result of their participation in the program (Appendix B). The affect category held statistical significance for only two questions, however these questions are interesting as they were most directly tied to teacher-participants' affect towards environmental education in general as well as their desire to implement it in their own classrooms.

\section{Section 4: Follow-up form Quantitative and Qualitative Results}

This section includes data from questions on the follow-up form regarding the participants' perceived efficacy in their ability to implement the Creeks and Kids workshop curricula and evidence of any implemented changes in inquiry teaching practices. The purpose of this report is to find out if there is any initial indication that the impact Creeks and Kids had on teacher-participants is in any way sustained over 
time. Results are organized as follows: a) results on how many activities participants have used from the workshop; b) results on people participants have shared curriculum and experiences with in their educational settings; and, c) direct quotes separated into themes. Numbers such as (012) are given as substitutes for teacher-participants' names to ensure confidentiality.

Results from the question, "How many different activities (from Stream Scene, Project WET and Project WILD Aquatic) have you implemented since taking the Creeks and Kids Workshop?" are as follows:

- Participant 004 implemented between 0-5 activities;

- Participants 008 and 012 implemented between 6-10 activities;

- Participants 005, 009 and 013 implemented between 11-20 activities.

- Participants 004 and 012 also implemented the Salmon and Trout Enhancement Program (STEP) within their classrooms. The STEP biologist instructor at Creeks and Kids informed participants of the opportunity for teachers to engage their students in salmon and trout restoration by raising eggs in the classroom and then working with local STEP biologists to release hatched fry into local streams.

Please indicate with whom you have shared your experiences and/or curricula from the Creeks and Kids workshop

Table 4.11 shows participant responses to the follow-up form question that asks them to "Please indicate with whom you have shared your experiences and/or curricula from the Creeks and Kids Workshop." These results directly connect to Professional 
Development Standard A regarding the criteria for teacher collaboration, and Standard $\mathrm{D}$, especially regarding the:

- Integration and coordination of the program components so that understanding and ability can be built over time, reinforced continuously, and practiced in a variety of situations.

- Collaboration among the people involved in programs, including teachers, teacher educators, teacher unions, scientists, administrators, policy makers, members of professional and scientific organizations, parents, and business people, with clear respect for the perspectives and expertise of each (NRC, 1996).

Table 4.11: Participant Responses to: "Please indicate with whom you have shared your experiences and/or curricula from the Creeks and Kids Workshop" ( $\mathrm{n}=6)$

\begin{tabular}{|c|c|c|c|c|}
\hline Participant & $\begin{array}{c}\text { Department/ } \\
\text { grade chair }\end{array}$ & $\begin{array}{c}\text { Teachers within } \\
\text { your department }\end{array}$ & $\begin{array}{c}\text { Teachers outside of } \\
\text { your department }\end{array}$ & $\begin{array}{c}\text { Teachers in other } \\
\text { schools }\end{array}$ \\
\hline 004 & N/A & None indicated & $\begin{array}{l}\text { Yes, 1high school } \\
\text { teacher }\end{array}$ & $\begin{array}{c}\text { Yes, teachers from } \\
5 \text { other schools } \\
\text { during Outdoor } \\
\text { School }\end{array}$ \\
\hline 005 & N/A & N/A & N/A & $\begin{array}{c}\text { Yes, } 28 \text { in K-12 } \\
\text { schools and } 17 \text { in } \\
\text { nonformal } \\
\text { education centers }\end{array}$ \\
\hline 008 & N/A & $\begin{array}{l}\text { Yes, grade level } \\
\text { team }\end{array}$ & $\begin{array}{c}\text { Yes, other grade level } \\
\text { teams }\end{array}$ & Yes, $>12$ teachers \\
\hline 009 & Yes & Yes, 4 teachers & Yes, 4 teachers & $\begin{array}{l}\text { Yes. Several at a } \\
\text { Project WILD } \\
\text { Early Learners } \\
\text { Workshop }\end{array}$ \\
\hline 012 & Yes & Yes, 8 teachers & $\begin{array}{l}\text { Yes. Several (\# not } \\
\text { indicated) }\end{array}$ & $\begin{array}{c}\text { Yes. Several } \\
\text { through district } \\
\text { science workshops }\end{array}$ \\
\hline 013 & Yes & Yes, 1 teacher & None indicated & None indicated \\
\hline
\end{tabular}


Out of the six participants who returned follow-up forms, 50\% indicated that they shared their experiences and the curricula from the Creeks and Kids Workshop with their department or grade-level chair. A total of $67 \%$ of this subset of respondents shared this information with teachers within their own departments, and again the same percentage, or four of the six respondents, shared this information with teachers in their schools who were outside of their own departments. Five of the six $(83 \%)$ respondents shared their experiences and/or the curricula from Creeks and Kids with teachers in other schools.

Direct quotes from participants on the follow-up form separated into themes:

\section{Theme 1: Confidence}

- "By taking the workshop in such an in-depth manner, I gained the confidence to actually implement the materials. I have been sitting on Project WET and Project WILD Aquatic since 1989 and have rarely broken open the books. Now they are a regular part of what I teach.” (009, Follow-up form).

- "I have the confidence and knowledge now to take the kids out in the field and explore - for example we look at macroinvertebrates in the river and compare them to the macroinvertebrates in the marsh system" (008).

These quotes offer a snapshot of the overall responses. Each participant who

filled out a follow-up form indicated some instance of Creeks and Kids that increased their confidence to teach about environmental education and to use the outdoors as a classroom. 


\section{Theme 2: Change in Teaching Practice}

- 'I've included exercises and more hands-on activities in every class that before were very much lecture-based" (013).

- "I used to think I had to stick strictly to the textbook, but I know now I can still teach to the curriculum and bring environmental education into the classroom"(012).

- "I definitely engage students more in discussions about behaviors and attitudes towards the environment and watersheds! Just today, we did a lesson from Project WET relating to trash in the oceans. This is part of our look at watersheds and how our released salmon might be affected by litter from our playground. The kids also felt terrible about sea turtles eating plastic bags and balloons. They are going to speak to the rest of the school at the morning meeting about the hazards of littering" (009).

Each respondent commented on some way in which his or her teaching practice changed after participating in Creeks and Kids. The workshop helped teachers to learn new ways to deliver curriculum and introduce environmental education into their classrooms. These results directly connect to the criteria addressed across Professional Development Standards A-D. Creeks and Kids staff demonstrated Standards A-D by: 1) encouraging teachers to collaborate with colleagues (Standard A); 2) allowing teachers to build upon their own knowledge and struggle with real classroom implementation situations (Standard B); 3) giving teachers support through continued networking and sharing of teacher-participant expertise (Standard C); 4) providing contacts with Creeks and Kids staff and local community scientists year-round, even after the workshop ended (Standard C); and , 5) provided clear, shared goals based on a vision of science 
learning, teaching, and teacher development congruent with the National Science Education Standards (NRC, 1996).

\section{Section 5: Observations and Notes from the Researcher as a Participant-Observer}

The purpose of the results in this section is to add observations from the perspective of the researcher as observer and participant. A mixed methods case study that is as highly qualitative as this one should be thorough and complete in the reporting of all qualitative results. This section adds some qualitative results from events and interactions observed by the researcher during the Creeks and Kids Workshop. It is organized into six subsections: 5a) a description of the setting of the Creeks and Kids Workshop and observations of teacher-participants and instructors; 5b) direct quotes from the workshop leader/Teacher Education Specialist in order to frame the purpose of the workshop and the staff's approach to environmental education; 5c) direct quotes from informal conversations with teacher-participants; 5d) direct quotes from instructors during classroom instruction and field activities; 5e) a conversation about how the Creeks and Kids program addresses standards and benchmarks in education; and, 5f) the Oregon Plan and its significance to watershed education. 


\section{5a: The setting of Creeks and Kids and the instructor team}

The participants arrived on an exceptionally warm day at Lake Creek Camp in the Strawberry Mountain Wilderness of southeast Oregon to spend four days learning about watersheds. The first event of the program took participants on a 5-mile drive to the top of a breathtaking vista point. Every year, the Creeks and Kids workshop leader and instructors take teachers to this viewpoint to introduce the concept of a watershed. Six different watersheds were in full view from the vista, and instructors offered information and visual cues to help participants delineate where each watershed was in relation to the next. Participants asked questions and took pictures until this introductory and very casual activity ended. For many participants, this was their very first glimpse of a watershed and was the visual introduction they needed to cultivate an understanding of the nature of a watershed.

Once back in what would be for the next four days the indoor activity and lesson classroom, participants were introduced to both the schedule of events and the instructors who would lead them. There were six instructors in the program, including a map and navigation specialist, a fish biologist, a macroinvertebrates specialist, a water quality expert, a naturalist and wildlife ecologist and a multi-talented classroom schoolteacher who specialized in helping teachers integrate the theme of water into their own classrooms.

The classroom schoolteacher began with, "Every child loves water, and has some experience with it to which they can connect". He set the stage for the Creeks and Kids' cross-curricular focus on water - a theme that he mentioned that can be integrated 
into any curriculum and used in any classroom. He continued to explain his personal experience and success teaching watershed education in his own classroom. The instructor described "Paddle to the Sea"--a book that inspired him to create a yearlong learning journey for students that traces the path of water through the watershed. As the year goes on, students get to move their canoes across a river that runs along the walls of the classroom each time they meet a learning goal. As he opened it up to teacherparticipants' questions and gave them the opportunity to share their own experiences with the group, the once-weary faces of the teachers who had traveled from all over the Pacific Northwest that day to learn and grow as professionals were now reflecting a pronounced interest and enthusiasm for what was to come.

\section{5b: Direct quotes from the workshop leader to frame the purpose of the workshop and its approach to environmental education:}

The following is a complete, unedited written response from the Creeks and Kids Workshop leader regarding environmental education (EE), teacher implementation of Creeks and Kids curriculum and instruction and the workshop's overall objectives:

(Begin Quote): My words for EE (with regard to Creeks and Kids) are summed up in the following paragraph:

Giving educators the opportunity to conduct interdisciplinary explorations of aquatic habitats with field excursions to local sites and investigate contemporary issues helping our children to be active, informed and enthusiastic learners. 
Concerning your questions (the researcher's) about implementation: Educators do not implement because: 1) they do not have content knowledge; and, 2) therefore do not feel comfortable with delivery. We provide relevant content and help them to become comfortable in at least one of the five areas of emphasis: fish sampling, mapping, macroinvertebrates, and water quality and wildlife inventory--with all of these curriculum activities meeting Oregon's educational standards.

Listed below are the five major objectives identified for the workshops:

1. Explore grade-level appropriate integrated curricular themes based on local watersheds and their parts.

2. Explore opportunities for using local habitats to supplement classroom instruction.

3. Participate in field activities and learn ways to enhance an integrated science curriculum by studying watersheds.

4. Explore techniques for field journals and nature drawing.

5. Learn how to incorporate language, art, and literature into the science curriculum.

6. Become comfortably efficient in at least one of the content areas for the purpose of passionate delivery for good, real learning. (End Quote).

This response from the workshop leader is discussed in the next section of this paper regarding its relevance to an environment-based education approach to professional development.

\section{5c: Direct quotes from informal conversations with teacher-participants:}

- "They (other teachers, administrators) say 'we want to get all we can out of these kids', aren't we supposed to give all we can to these kids? Teachers (at my school) are treated like sheep-herded like the kids, (so it) feels like 
teachers are competing instead of working together. This workshop helps fill me the gaps so that I can give all I can to the kids. " (014).

- 'I can’t believe it, there's only one day left, I don't want it to end!" (009).

These quotes offer two separate but related glimpses into subjects brought up by the teacher-participants. The first quote is but one example of the data gathered during informal conversations about teacher-participants' school environments and their previous experiences with professional development. Many of the teachers brought up that, in addition to the lack of collaboration between teachers in their schools, previous professional development experiences they had did not encourage a lot of collaboration or sharing of experiences.

The second quote offers an example of the general air of enthusiasm and engagement that participants had during the four days of the workshop. Teachers worked with one another, bounced ideas around together and shared stories and experiences. The National Research Council's Professional Development Standard B is represented in these results (1996). The instructor team continually encouraged participants to learn from each other, mentioning that they are stronger when they work together. It became clear that participants were receptive to the kind of treatment they received from the instructor team that was not always present in their school environments. Participants mentioned how much they appreciated the respect and encouragement the instructors gave them. 


\section{5d: Direct quotes from instructors during classroom and field activities:}

- "Working with kids is great, but working with the people who change their lives is heart stopping!" (instructor 004).

- "Some things have to be experienced. They cannot come from a book or an explanation" (instructor 005).

- "Teachers are hungry for this, so why would we deny them of it?" (instructor 004, when speaking of field study and outdoor activities to learn).

- “Ask yourself and your students, because we don't often enough, 'How does science touch me emotionally? How am I connected?' (instructor 003).

Instructors were professional and always modeled the behavior and teaching practices from which they believed teacher-participants could benefit. They modeled questioning and active teaching strategies through inquiry-guided activities and field study so that participants could gain the skills and confidence to do the same with their own students. It was clear from observing and speaking with the instructors that they were passionate about their role within the Creeks and Kids Workshop and that they truly cared about the professional and personal growth of the participants as teachers.

\section{5e: A conversation about how Creeks and Kids addresses standards and benchmarks in education:}

Standards and benchmarks are a common point of concern for many teachers. The issue of if and how the Creeks and Kids curriculum adheres to standards was discussed during indoor classroom time at the workshop and was not lost on the Creeks 
and Kids instructors who had thoughts on teachers' school environments. A summary of direct quotes in two sub-sections below reveal how instructors felt it important to speak about this topic and explain the way in which the instructor team aims to be aware of what teachers face:

\section{$\underline{\text { Direct comments instructors made to teacher-participants }}$}

- “This isn't wrapped around benchmarks - that issue is intense enough for you at school—we want to treat you as smart, intelligent adults who can figure (those connections) out on your own" (workshop leader).

\section{Direct comments instructors made to the researcher}

- 'I don't think they (teachers) get the support to go with their passion. There's so much pressure to meet standards and benchmarks, and that trickles down from the state, district, principal and other teachers" (002).

- "The nice thing about Creeks and Kids is that it lets you know that benchmarks is not what it's all about. (Creeks and Kids) does meet the standards, but there is far more to education than the benchmarks and standards, and that it is OK for teachers to think that. Kids loving to learn is what it's all about" (002).

- 'It's a philosophy that if you're teaching good science, the standards are going to follow - if you're making it fun, it won't be difficult to follow standards. Especially within Creeks and Kids, it is the way you teach, it is a passion about teaching whatever part you are teaching. The important part is getting teachers passionate, and water is a great avenue to get people excited" (002).

At the same time, the instruction team continually showed participants where they could find assessment strategies and other information within the Creeks and Kids 
curriculum. There was no direct mention of the National Research Council's Standards for the Professional Development of Teachers of Science; however, as shown by the reported results in Chapter V of this paper, these Standards were addressed throughout the Creeks and Kids Workshop. Instructors highlighted pages of the Project WET and Project WILD Aquatic curriculum to describe how they encourage formative and summative assessment strategies as well as options for adapting the curriculum to various grade levels. The Stream Scene curriculum was discussed to explain that it adheres to Oregon education standards and that there are pre- post-assessments built directly into the curriculum for teachers.

The workshop leader and other Creeks and Kids instruction team members repeatedly reminded participants of the support they have to offer, even after the workshop is over. All teacher-participants who attended the workshop were encouraged to contact the workshop leader and the instructor team at any time for assistance with the curriculum and activities modeled during the workshop or with any further questions regarding issues such as connecting to standards. Teacher-participants were also encouraged to stay in touch with one another and, in addition, to contact previous year's teacher-participants for networking and support.

The responses given by the instructors regarding how a professional development program such as Creeks and Kids should address standards and benchmarks reveal that they put more emphasis on the need for good modeling of teaching practices and inciting enthusiasm in teachers to teach about water. The emphasis to analyze how Creeks and Kids adheres to the National Research Council's 
Standards for the Professional Development of Teachers of Science (1996) was solely an avenue the researcher wished to explore during this case study.

\section{The Oregon Plan and its significance to watershed education}

The Creeks and Kids Workshop yearly grant proposal reveals that one of the important long-term goals of the program is to increase citizens' exposure to watershed education for the improvement of salmon runs, trout populations, water quality and to restore the healthy function of watersheds throughout Oregon. The next paragraphs describe the researcher's observation of an instructor-facilitated discussion about the importance of watershed education in order to show how teachers, students, schools and communities might address these issues.

On the last day of the workshop, one of the instructors ended by reading aloud a story about the interconnectedness of humans and salmon. It was a story called "Down to the Sea", written to show the real meaning of the Oregon Plan. The Oregon Plan is a plan to get all Oregonians involved to restore native fish populations and the water systems that sustain them. After the story, the instructor talked about the Oregon Plan in the context of "knowing the rhythm of a place." He commented that an awareness, cultivated through watershed education, could help people foster a special connection to the environment to understand how we are a part of that rhythm:

The Oregon Plan goes beyond law-through environmental education, teachers like you are producing citizens who have a new view of watersheds and their importance - this is why watershed education itself is so important. We need to go beyond the law to restore the health of watersheds to change the 
relationships between humans and wildlife and salmon. How long will it take? As long as teachers like you are bringing watershed education into the classroom, we get a little closer. Everyone can benefit, and anyone can help.

The results reported here by the researcher serve to further clarify and/or support the already reported results from the teacher-participants and the Creeks and Kids staff. In addition, these observations have allowed for a closer look into the interactions between participant and participant, staff member and staff member, staff members and participants, and the details in the behind the scenes setup and preparations for the program itself. The researcher's descriptions of the intricacies of the workshop and its purpose also serve to strengthen how the Creeks and Kids Workshop directly connects to the criteria of all of the National Research Council's Standards for Professional Development of Teachers of Science; however, the researcher's observations reflect most the particular connections to Standard D. The criteria for this Standard D are listed below so that the reader need not go back to read it in the Literature Review of this paper:

\section{Professional Development Standard D}

Professional development programs for teachers of science must be coherent and integrated. Quality pre-service and in-service programs are characterized by:

- Clear, shared goals based on a vision of science learning, teaching, and teacher development congruent with the National Science Education Standards. 
- Integration and coordination of the program components so that understanding and ability can be built over time, reinforced continuously, and practiced in a variety of situations.

- Options that recognize the developmental nature of teacher professional growth and individual and group interests, as well as the needs of teachers who have varying degrees of experience, professional expertise, and proficiency.

- Collaboration among the people involved in programs, including teachers, teacher educators, teacher unions, scientists, administrators, policy makers, members of professional and scientific organizations, parents, and business people, with clear respect for the perspectives and expertise of each.

- Recognition of the history, culture and organization of the school environment.

- Continuous program assessment that captures the perspectives of all those involved, uses a variety of strategies, focuses on the process and effects of the program, and feeds directly into program improvement and evaluation. 


\section{Chapter V: Discussion}

The purpose of this study was to find out what teachers need to implement environment-based education (EBE) in their educational settings and to reveal their beliefs regarding what professional development should provide in relation to those needs. This mixed-methods approach included a qualitative description of teacherparticipants' experiences during the workshop and a quantitative measurement of the program's success in helping participants meet learning outcomes and goals. The results of the study revealed that teachers need an EBE professional development program to include:

- Practical ways to instantly integrate environmental education into their existing curricula and school settings; and,

- Direct experience with interdisciplinary, hands-on, inquiry-guided activities and field study.

Teacher-participants identified these characteristics as vital for them to effect a change in teaching practice and build their confidence to implement EBE with their students when they return to the classroom.

This section will discuss the results in relation to the original research question and the points made in the introduction of this paper. 
The original research question was:

What were the experiences of the teacher participants during the Creeks and Kids Watershed Education workshop and how did those experiences influence their views on their teaching practice as it relates to implementing EBE in their schools?

This study found that the quality of curriculum, instruction and support given by the Creeks and Kids staff helped increase participants' confidence to implement EBE after the workshop. These findings speak to Ernst's recommendations that professional development (PD) and delivery of teacher training must operate from a better understanding of teachers' perceived barriers to EBE implementation (2009). Ernst asserts that PD should give teachers opportunities to learn and practice strategies that will help them negotiate the barriers they perceive as most strongly constraining them from implementing EBE. The Creeks and Kids instructor team operates within this understanding from day one of the workshop and continually provides high-quality instruction, formative and summative assessment, encouragement and a network of long-term support to set up all teacher-participants for success both during and after the workshop.

It is clear from the data that teacher-participants' confidence to conduct interdisciplinary, inquiry-guided activities and field studies related to the theme of water and watersheds increased because of the hands-on experiences and practical implementation strategies they learned during the workshop. The quote in Chapter V's results section $4 \mathrm{c}$ that highlighted the participant who indicated that $\mathrm{s} / \mathrm{he}$ had not used 
Project WET or WILD Aquatic for over 21 years provides a great example that supports this claim. This speaks to a point made in the introduction. This point indicated that though interdisciplinary, water-focused curriculum is not necessarily new to teachers, it is rare that it is modeled in ways that teachers can use readily. The results of this study suggest that professional development that simply gives out curriculum--especially inquiry-guided and hands-on curriculum that encourages field study--without recognizing the need to model effective delivery of content and give participants the chance to do it themselves does not serve the needs of teachers who want to implement EBE.

The introduction highlighted that teachers need to be in collaborative professional development (PD) environments in which the best sources of expertise link with the experiences and current needs of teachers. This is also a criterion of the Standards for Professional Development for Teachers of Science (NRC, 1996). The results of this study show that the modeling of best practices by the instructors on how to use water as an integrating context for learning across disciplines inspired teacherparticipants' self-efficacy to use these environment-based strategies in their own school settings. These results also illuminate the positive effect that quality PD instruction has on teachers' efficacy and confidence to implement environment-based education and align with the findings of Kenney et. al (2003) as described in the literature review. These results further support that the Creeks and Kids Workshop adheres to the National Research Council's Standards for Professional Development for Teachers of Science as mentioned in both the Literature Review and Results sections of this study. 
The introduction addressed that teachers need interdisciplinary professional development that emphasizes networking and collaborating with other teachers. These are important components of Standard B from the Standards for Professional Development for Teachers of Science (NRC, 1996). Though challenges existed for teacher-participants when working with their peers during the Creeks and Kids Workshop, their overall response was that they learned best with their peers, collaborating and sharing ideas with each other. These results are also connected to the data surrounding teacher-participants' increased confidence. Teachers indicated that their confidence strengthened due to the workshop's emphasis on collaboration, group work and the sharing of stories with peers. After Creeks and Kids, teacher-participants wanted to share their enthusiasm for what they learned with administrators and other colleagues at their schools. These results support the findings of Meichtry \& Harrell (2002) regarding networking and the support that teachers need from professional development, and the findings of Lieberman \& Hoody (1998) on the positive outcomes for teachers and their relationships with colleagues that result from an EBE approach to teaching and learning.

The results of the Creeks and Kids study add to research regarding teachers' perceived benefits of thematic instruction (Brody, 1995; Stapp, 1996; 2000). Data indicated that teachers believed the Creeks and Kids' environment-based educational approach helped them engage students to put environmental education into action locally in their schools and communities while still allowing them to teach across their required multiple-subjects curriculum. Echoed in these results is criterion from Standard 
D of the Standards for Professional Development for Teachers of Science. This connection supports the environment-based education model of Creeks and Kids that approaches curriculum and instruction from a perspective that recognizes the culture and organization of various school environments. By adhering to Standard D, the workshop's teacher-participants are equipped with the tools they need implement EBE effectively in their own classrooms.

As Robertson \& Krugly-Smolska (1997) assert, few researchers have adequately addressed the challenge environmental education (EE) represents to existing patterns of schooling, and the inability of most EE providers to recognize the realities of the classroom and the implementation needs of teachers. The Creeks and Kids Workshop challenges some existing patterns of education due to its interdisciplinary, inquiryoriented nature and through its emphasis on outdoor field study, but it does not do so in a way that contradicts certain realities in the participants' schools. Supporting this are the results that reflect how teachers could instantly see the feasibility of using what they learned at Creeks and Kids with their students. These results speak to Ernst's call for efforts to make EBE a more accessible, formal instructional approach (2009). Many of the instructors, including the workshop leader, are or have been formal classroom teachers. They are keenly aware that teachers must meet standards and benchmarks, however, they are also highly adept in innovative, economical, yet fun and practical ways to implement quality EBE curriculum that meets state standards. They realize that teachers' needs are determined both by the variety of learners they serve and the school and communities in which they teach. In this way, the Creeks and Kids Workshop 
offers teacher-participants a real and practical approach that is closely aligned with using the EBE models described by Ernst (2009) and Lieberman \& Hoody (1998).

The direct quote of the workshop leader in section $5 \mathrm{~b}$ of the results reveals the mission of Creeks and Kids to "give educators the opportunity to conduct interdisciplinary explorations of aquatic habitats with field excursions to local sites and investigate contemporary issues helping our children to be active, informed and enthusiastic learners." Fostering the qualities of active, informed and enthusiastic learning is one of the main goals of environment-based education (EBE) (Lieberman \& Hoody, 1998). It is also one of the main criteria linked to the National Research Council's Standards for Professional Development for Teachers of Science regarding the need to let teachers' inquiry learning abilities strengthen over time, be reinforced continuously, and be practiced in a variety of situations (1996). In addition, the results describing the teacher-participants' experiences during the Creeks and Kids Workshop show that this program has the ability to continue to inspire future teacher-participants toward active learning and investigating phenomena as indicated in the Professional Development Standards (NRC, 1996).

The findings of the Creeks and Kids study have broader implications for educational research on how EBE in professional development can serve the needs of teachers to promote critical thinking and problem solving skills in their students. Ernst \& Monroe (2004) assert that professional development in EBE can support teachers to implement practical and effective ways to improve students' critical thinking skills and knowledge across disciplines. The authors cite McTighe \& Schollenberge (1991), who 
state that the goal of improving critical thinking is fundamental to education in America, especially due to the increasingly complex societal challenges that call for an improvement in the thinking skills used by decision-makers and citizens in their daily affairs (Ernst \& Monroe, 2004). The development of critical thinking skills is paramount as the challenges facing our world evolve. As stated in the introduction of this paper, the charge to create awareness about water issues and empower people to create sustainable solutions to protect the availability and health of water is one of the most important educational challenges of our age. Without critical thinking and problem-solving skills grounded in real world environment issues, this will not be a challenge current and future students will overcome. 


\section{Chapter VI: Conclusion}

To demonstrate the characteristics of the Creeks and Kids Workshop that highlight it as an environment-based education (EBE) professional development program, this pilot case study reported findings on how the curriculum and instruction of the workshop had a positive impact on teacher-participants' knowledge gains from, affect toward, and confidence and efficacy to implement EBE about water and watersheds. In addition, very few studies on environmental education approaches directly examine the views of the teachers (Robertson \& Krugly-Smolska, 1997). The Creeks and Kids study provided a way to give voice to some of the teachers who are dedicated to their profession and are guiding the minds of the students of the Pacific Northwest.

Previous literature is light on offering direct evidence of successful models of professional development that engage teachers in environment-based education (EBE). There is also limited research that directly evaluates a professional development program that uses an EBE approach while connecting the program to the National Research Council's Standards for Professional Development for Teachers of Science (1996). Research evaluating the successes of environment-based education has focused mostly on the positive effects EBE in-school programs have on students. Though researchers acknowledge the need to find out the factors that influence teachers' implementation of EBE, little attention is given to studying professional development programs that model an EBE approach. This approach to teaching and learning is 
modeled in the Creeks and Kids Workshop, which also provides for the long-term support of teacher-participants in their EBE implementation efforts and adheres to many of the Standards for Professional Development for Teachers of Science.

The results of the Creeks and Kids study support the notion that other environmental education professional development programs (EEPD) may benefit from using themes such as water to teach across disciplines, as some programs already do. However, more emphasis needs to be placed on using the environment and community in and around schools to teach across disciplines, and model and engage teachers in these methods so that they can make interdisciplinary environmental education a regular and more deeply embedded part of everyday curriculum and instruction. The focus of many EEPD programs is to promote the knowledge acquisition of environmental education topics. While knowledge is important, this approach places less emphasis on creating a direct connection between the person and the topic. The Creeks and Kids model immediately promotes a direct connection between teacher-participants' and their personal connection to water so that they can understand how to help students connect to their own experiences with a topic or an issue. Teachers are empowered to use the theme of water to elicit their students' connections to it through the implementation of Creeks and Kids' thought-provoking inquiry activities, lessons and field studies.

The National Research Council emphasizes that what students learn is greatly influenced by how they are taught (1996). A principal of one of the teachers involved in 
an EBE program titled STREAMS (Lieberman \& Hoody, 1998), said in an interview:

"We cannot continue to teach the way we were taught...the future of education depends on these (environment-based) programs and the people dedicated to teaching them". The Creeks and Kids Workshop indeed demonstrates a successful environment-based education approach to professional development that supports teachers to teach in a different way than they themselves were taught.

One of the concerns of this study was that on the pre-workshop questionnaire, teacher-participants' were not asked about any perceived barriers to environmental education implementation in their classrooms. A further limitation of the study is that the researcher did not ask participants to define environmental education (EE), environment-based education (EBE), or to give their thoughts on these educational approaches. Though some data were gathered on teacher-participants' prior instructional approaches, it would have perhaps been advantageous to get more specific data from participants regarding their previous experience with any related EE or EBE strategies. The recommendations for future research include references to using reliable and valid instruments to focus specifically on either EBE or teacher efficacy, and then supplement the data gathered with thorough qualitative methods.

To support and/or add to the findings of this research, recommendations for future research include:

- Continue research on as many of the participants of the previous Creeks and Kids study to see how many elements of EBE they still incorporate in their teaching practice. It would be especially interesting to see if any 
teachers employed larger-scale collaboration using water as an integrating context, as demonstrated in the research of Lieberman \& Hoody (1998). This study would aim to find out if Creeks and Kids teacher-participants collaborated with other science, math, language arts and social studies teachers within their schools to use Creeks and Kids curriculum and instruction within their grade levels.

- To build upon the thought of the above recommendation, a study of the students of previous Creeks and Kids participants to see if EBE approaches employed are influencing students' regular subject matter testing, standardized test scores or overall critical thinking skills as identified by the teachers. Ernst \& Monroe (2004) have demonstrated that there is limited research documenting a connection between environment-based education and academic achievement.

- To perform another study of Creeks and Kids with the reliable and valid quantitative instruments used in the work of Ernst 2007; 2009 regarding the perceived barriers to implementing EBE in classrooms, but, in addition, building on this research with qualitative analysis to fill the gaps regarding teacher confidence to implement EBE. In addition, it would be interesting to incorporate quantitative measures to find any differences between teachers of varying years of science teaching and environmental education experience and correlate this with data from perceived barriers to implementation.

- Carry out a future study of Creeks and Kids with the instrument used by Moseley et. al (2002) to measure teacher confidence and self-efficacy after an environmental education professional development (EEPD) program. However, the gap in their findings about teacher self-efficacy should be addressed by using qualitative analysis to collect evidence about teachers' thoughts on if and how the EEPD program helped them 
build confidence to implement what they learned or to effect a change in their teaching practice.

These suggestions for future environment-based education research should include further analysis to make connections between professional development programs and the criteria of the National Research Council's Standards for Professional Development for Teachers of Science. If effective professional development (PD) programs like Creeks and Kids can be revealed and serve as models of the reforms to teaching and learning that the Standards call for, perhaps more science (and other disciplines') teacher preparation programs and PD programs will adopt these strategies early on. Further research that supports the effective strategies and positive effects of environment-based education in schools and communities could build teacher efficacy early in a teacher's career. This could lay a strong foundation for pre- and in-service teachers of science and other subjects to feel empowered to implement the quality interdisciplinary, hands-on and inquiry-guided instruction that makes collaboration with their peers a natural step toward the ultimate goal of empowering all students. 


\section{Literature Cited}

Araya, Y.N., \& Moyer, E.H. (2006). Global public water education: The World Water Monitoring Day experience. Applied Environmental Education and Communication: An International Journal, 5(4), 263-267.

Austin, T., House-Peters, L., Skees-Gregory, D. (2009). Perceptions of the removal of Marmot Dam and the draining of Roslyn Lake: An ecosystem services case study in Sandy, Oregon. Unpublished paper.

Brody, M. (1995). Development of a curriculum framework for water education for educators, scientists, and resource managers. Journal of Environmental Education, 26(4), 18-29.

Chitale, M.A. \& Cederwall, K. (2001). Making water everybody's business - the educational challenge. Synthesis. Water Science and Technology, 43(4), 165166.

Colbert, J., Brown, R., Choi, S., \& Thomas, S. (2008). An investigation of the impacts of teacher-driven professional development on pedagogy and student learning. Teacher Education Quarterly, 35(2), 135-154. Retrieved from ERIC database.

Creswell, J.W., \& Plano Clark, V. L. (2007). Designing and conducting mixed methods research. Thousand Oaks, CA: Sage.

Creswell, J.W. (2008). Educational research: Planning, conducting and evaluating quantitative and qualitative research. $\left(3^{\text {rd }}\right.$ ed.). Upper Saddle Creek, NJ: Pearson Education.

Ernst, J., \& Monroe, M. (2004). The effects of environment-based education on students' critical thinking skills and disposition toward critical thinking. Environmental Education Research, 10, 507-522.

Ernst, J. (2007). Factors associated with K-12 teachers' use of environment-based education. Journal of Environmental Education, 38(3), 15-31.

Ernst, J. (2009). Influences on US middle school teachers' use of environment-based education. Environmental Education Research, 15:1, 71-92.

Giolitto, P., \& Souchon, C. (1991). Environmental education in France: Assessment and outlook. European Journal of Education, 26(4), 307-13. 
Gruver, J., \& Luloff, A. (2008). Engaging Pennsylvania teachers in watershed education. Journal of Environmental Education, 40(1), 43-54. Retrieved from Professional Development Collection database.

Jackson, S. (2003). Research methods and statistics: A critical thinking approach. Belmont, CA: Wadsworth.

Kenney, J., Militana, H., \& Donohue, M. (2003). Helping teachers to use their school's backyard as an outdoor classroom: A report on the Watershed Learning Center Program. Journal of Environmental Education, 35(1), 18-26. Retrieved from Professional Development Collection database.

Kilibarda, K. A study of the relationship between participation in professional development and teachers' science efficacy, attitudes, and classroom practices. Ed.D. dissertation, Drake University, United States -- Iowa. Retrieved June 1, 2010, from Dissertations \& Theses: Full Text. (Publication No. AAT 3237043).

Klein, P. (1995). Using inquiry to enhance the learning and appreciation of geography. Journal of Geography, 94(2), 358-67.

Leech, N., \& Onwuegbuzie, A. (2007). An array of qualitative data analysis tools: A call for data analysis triangulation. School Psychology Quarterly, 22(4), 557584.

Lieberman, G., \& Hoody, L. (1998). Closing the achievement gap: Using the environment as an integrating context for learning. San Diego, CA: State Education and Environment Roundtable.

Lumpe, A.T., Haney, J.J., \& Czerniak, C.M. (2000). Assessing teachers' beliefs about their science teaching context. Journal of Research in Science Teaching, 37, 275-292.

Meichtry, Y., \& Harrell, L. (2002). An environmental education needs assessment of K12 teachers in Kentucky. The Journal of Environmental Education, 33(3), 21-26.

Meichtry, Y., \& Smith, J. (2007). The Impact of a place-based professional development program on teachers' confidence, attitudes, and classroom practices. Journal of Environmental Education, 38(2), 15-32. Retrieved from Academic Search Complete database. 
Moseley, C., Reinke, K., \& Bookout, V. (2002). The effect of teaching outdoor environmental education on pre-service teachers' attitudes toward self-efficacy and outcome expectancy. Journal of Environmental Education, 34(1), 9. Retrieved from Professional Development Collection database.

NAAEE \& NEETF. (2001). The North American Association for Environmental Education (NAAEE) and The National Environmental Education and Training Foundation (NEETF). Using environment-based education to advance learning skills and character development. Washington, DC: NAAEE and NEETF.

National Research Council (1996). National Science Education Standards. Washington, DC: National Academy Press.

Project WET (1995). Water education for teachers. Bozeman, Montana: The Watercourse and Western Regional Environmental Education Council.

Roberts, M. Lesson study: Professional development and its impact on science teacher self-efficacy. Ed.D. dissertation, Teachers College, Columbia University, United States -- New York. Retrieved June 14, 2010, from Dissertations \& Theses: Full Text. (Publication No. AAT 3400659).

Robertson, C., \& Krugly-Smolska, E. (1997). Gaps between advocated practices and teaching realities in environmental education. Environmental Education Research, 3(3), 311. Retrieved from Professional Development Collection database.

Ross, J., \& Bruce, C. (2007). Professional development effects on teacher efficacy: Results of a randomized field trial. Journal of Educational Research, 101(1), 5060. Retrieved from ERIC database.

Salyer, B.A., \& Crawley, F.E. (1995). Origins of life science teachers' beliefs underlying curriculum reform in Texas. Science Education, 79(6), 611.

Shepardson, D.P., Harbor, J., Cooper, B., \& McDonald, J. (2002). The impact of a professional development program on teachers' understandings about watersheds, water quality, and stream monitoring. Journal of Environmental Education, 33(3), 34-40.

Simmons, D. (1993). Facilitating teachers' use of natural areas: Perceptions of environmental education opportunities. The Journal of Environmental Education, 24(3) 8-16. 
Supovitz, J.A., \& Turner, H.M. (2000). The effects of professional development on science teaching practices and classroom culture. Journal of Research in Science Teaching, 37(9), 963-980.

Stapp, W.B., Cromwell, M., Schmidt, D., \& Alm, A. (1996). Investigating streams and rivers. Dubuque, IA: Kendall-Hunt.

Stapp, W.B. (2000). Watershed education for sustainable development. Journal of Science Education and Technology, 9(3), 183-197.

Trochim, W. \& Donnelly, J.P. (2007). The research methods knowledge base. ( $3^{\text {rd }}$ ed.). Mason, $\mathrm{OH}$ : Thomson Publishing.

United Nations World Water Assessment Programme (UNWWAP). (2009). United Nations World Water Assessment Programme. The World Water Development Report 3: Water in a Changing World. UNESCO: Paris, France.

Young, C., \& Simmons, D. (1992). Urban teachers' perspectives on teaching natural resources. Women in Natural Research, 13(3), 39-43.

Volk, T. L., \& McBeth, B. (1998). Environmental literacy in the United States: What should be ... what is ... getting from here to there. Washington, DC: North American Association for Environmental Education. 


\section{Appendix A: Demographics and Instructors' Backgrounds}

Figure A.1: Type of Facility where Creeks and Kids Workshop Participants Teach (Item 9 on Pre-workshop questionnaire)

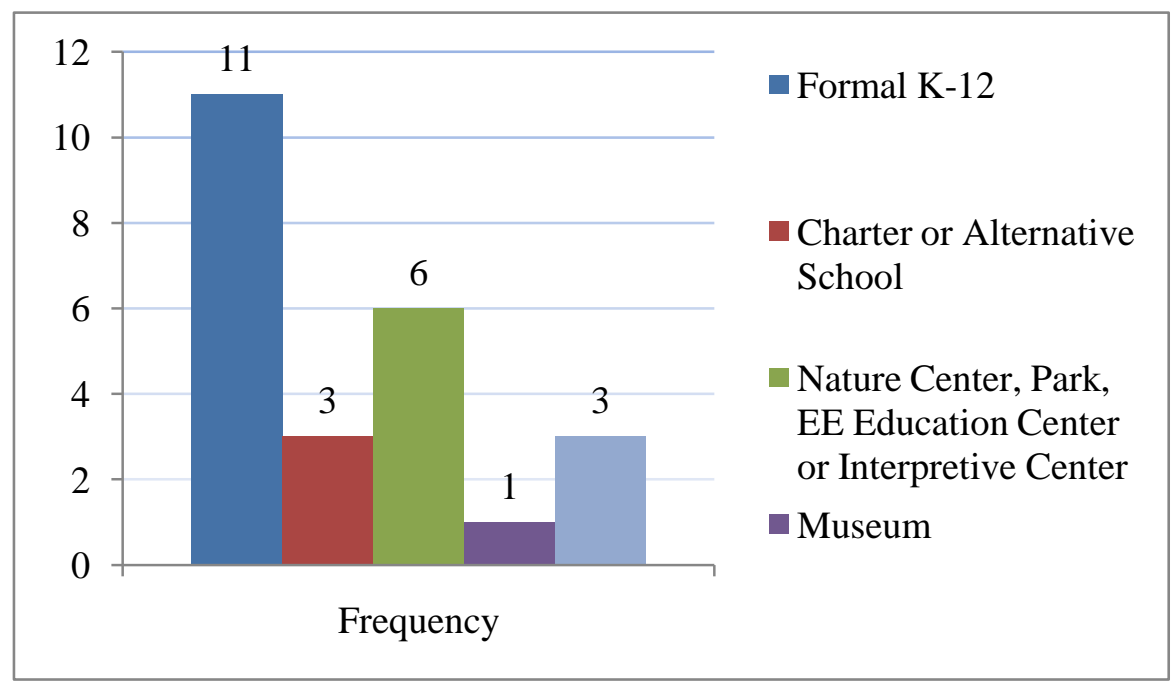

Table A.1: Teaching Endorsements Held by Creeks and Kids Workshop Participants ( $\mathrm{n}=14)$

\begin{tabular}{|l|c|}
\hline \multicolumn{1}{|c|}{ Endorsement } & Count (\% of total sample) \\
\hline Elementary & $2(14 \%)$ \\
\hline Middle School multiple subjects & $2(14 \%)$ \\
\hline Integrated Science for High School & $1(7 \%)$ \\
\hline English for Speakers of other Languages (ESOL) & $3(21 \%)$ \\
\hline Special Education & $2(14 \%)$ \\
\hline Reading & $4(26 \%)$ \\
\hline Social Sciences & $1(7 \%)$ \\
\hline Health Education K-8 & $1(7 \%)$ \\
\hline Not Applicable/No Endorsement & $4(26 \%)$ \\
\hline
\end{tabular}


Table A.2: Background *EE Characteristics of summer 2009 Creeks and Kids Workshop Participants $(\mathrm{n}=14)$

\begin{tabular}{|c|c|c|c|}
\hline $\begin{array}{c}\text { *EE Coursework taken in } \\
\text { college } \\
\text { (Item 11) }\end{array}$ & Frequency & $\begin{array}{c}\text { *EE Professional } \\
\text { Development Experience } \\
\text { (Item 12) }\end{array}$ & Frequency \\
\hline $\begin{array}{c}\text { Environmental Science } \\
\text { Course }\end{array}$ & 3 & Project Learning Tree & 3 \\
\hline $\begin{array}{c}\text { Agriculture Course } \\
\text { Forestry Course }\end{array}$ & 1 & Project WET & 4 \\
\hline Garden Education Course & 2 & Project WILD Aquatic & 4 \\
\hline Watershed Education Course & 3 & Creeks and Kids & 1 \\
\hline Not Applicable/None & 5 & Ecological Inquiry & 2 \\
\hline & & Climate Change Workshop & 1 \\
\hline & & Wetlands Workshop & 4 \\
\hline & & Gardens \& Invasive Species & 2 \\
\hline & & Not Applicable/None & 4 \\
\hline
\end{tabular}

*EE is the abbreviation for environmental education 


\section{Creeks and Kids Instructors' Backgrounds}

Creeks \& Kids was designed by Oregon Department of Fish and Wildlife staff, other agency staff, teachers, and fish and wildlife experts. Many of the same people who started with Creeks and Kids are still involved including some of the instructors below. Six instructors participated in the 2009 Creeks and Kids Workshop during this study. Below is a summary of 1) brief background of each instructor; 2) years each instructor has participated in Creeks and Kids; and 3) the current position the instructor holds within and outside the Creeks and Kids program. All instructors, listed below, were specifically recruited by the Teacher Education Specialist of Jackson Bottom Wetlands Preserve who runs the Creeks and Kids Workshop.

1. Instructor (001): Before and after experience with Creeks and Kids Workshop held position as a Wetlands Education Specialist at Jackson Bottom Wetlands Preserve. Has taught at Creeks and Kids Workshop every year since 2002. The Teacher Education Specialist of Jackson Bottom who is the Coordinator of Creeks and Kids wanted to bring the wildlife station back to the Creeks and Kids program, so that is how this instructor became involved in the program as an instructor. This instructor usually teaches middle school-aged children, so really enjoys working with teachers during the Creeks and Kids Workshop.

2. Instructor (002): Before and after experience with Creeks and Kids Workshop held position as a middle school science teacher. Attended Creeks and Kids as a participant in 2005 and was asked to be an instructor starting in 2006 until present (2009). Shares activities s/he directly implements in his/her own classroom with the teacher-participants of the Creeks and Kids Workshop every year. Direct implementation information and connection for participants through this instructor. 
3. Instructor (004): Before and after Creeks and Kids experience is an educator at Jackson Bottom Wetlands Preserve and specializes in macroinvertebrate study. Has participated in Creeks and Kids for three years.

4. Instructor (005): Participated in Creeks and Kids as a teacher-participant for four years. Is now a retired teacher, has been doing Creeks and Kids mapping for around 10 years.

5. Instructor (006): Has been a watershed instructor for over 10 years. Teaches about water and water quality. Has been with Creeks and Kids about as long as the Teacher Education Specialist who runs Creeks and Kids. One of the original developers of the Creeks and Kids curriculum and program.

6. Instructor (007): Oregon Salmon and Trout Enhancement (STEP) Biologist. First time teaching at 2009 Creeks and Kids Workshop. Recruited by Teacher Education Specialist and there for emphasis on fish ecology and scientist-teacher partnerships. Stresses the importance of utilizing local STEP Biologist in community and developing relationships with scientists and landowners for stream and fish habitat restoration.

7. Teacher Education Specialist/Director of Creeks and Kids: Has been involved with Creeks and Kids since 1988. Originally started as a teacherparticipant. Developed many teacher-scientist partnerships and eventually helped edit the program curriculum for an advanced biology class. Long-time high school science teacher in biology and became involved in running the Creeks and Kids Workshop shortly after participating in it as a teacher. Responsible for coordinating Creeks and Kids staff, program supplies, and all funding for the program. More information about the Teacher Education Specialist is in Appendix B throughout the description of the Creeks and Kids history and objectives and outcomes sections. 


\section{Appendix B: Description of the Creeks and Kids Workshop}

Portland State University's Center for Science Education partners with Jackson Bottom Wetlands Preserve to offer professional development and graduate credit for the Creeks and Kids Workshop, an environmental education program held every year for formal and non-formal educators. The Workshop is a watershed education program that is open to all educators who work with students and want to learn best practices in science and environmental education to encourage student learning about streams and watersheds. The Workshop ultimately aims to set up educators for success to use watersheds as learning sites for their students. The educators who participate in the Workshop are formal K-12 teachers, including pre and in-service teachers, non-formal K-12 educators such as museum educators, nature center educators, and educators from institutions and community groups, watershed councils, and those from federal, state and local agencies. This year's Workshop will run from July 20, 2009 to July 24, 2009 in the Strawberry Wilderness area of southeast Oregon. Participants share lodging, meals and rotate between groups during activities and presentations to maximize teamwork and group participation.

The Workshop curriculum draws from three sources: The Stream Scene, an active learning guide developed by the Oregon Department of Fish and Wildlife that emphasizes hands-on learning to gain knowledge about watersheds; Project WET, a guide for educators by educators about water education; and Project WILD Aquatic, an interdisciplinary conservation and environmental education program with a focus on wildlife. All three curricula focus on water and watersheds and provide a large selection of relevant and meaningful environmental education content for students to connect them to their local watershed. The materials were developed by educators to provide creative teaching strategies that accommodate an educator's needs to address diverse learning styles and create enthusiasm for science learning about watersheds and the 
environment. Learning strategies for the Creeks and Kids Workshop take the form of both fieldwork and classroom activities.

Over the course of 20 years more than 1000 educators have participated in the Creeks and Kids Workshop. The education staff of Creeks and Kids is comprised of seven members, from various backgrounds ranging from science teaching, biology research and education, educational consulting, positions with state and federal agencies and management experience in environmental groups.

\section{History and Further Description from the Yearly Proposal for Funding by Creeks and Kids Teacher Education Specialist}

\section{Activity Type: Education}

Creeks and Kids is a four day, time-tested, field based workshop for natural resource specialists, teachers, and individuals interested in aquatic-watershed education and involvement programs. Each year, 30 participants work with the Oregon Department of Fish \& Wildlife (ODFW), Jackson Bottom Wetlands, and other agency staff to gain skills in getting students involved in watershed education and restoration work. ODFW and Jackson Bottom Wetlands Preserve partnered to continue the 20 year history of providing this program. The majority of school activities in Oregon centered on watersheds and salmon had its beginnings in Creeks and Kids workshops.

The overall goal of the Creeks and Kids program is to increase citizen involvement in improving salmon and trout populations, improving water quality, and restoring watershed function, resulting in healthy watersheds throughout Oregon. Funding from ODFW R\&E will allow 30 participants per year including classroom teachers, museum educators, natural resource specialists, and agency staff to participate in Creeks and Kids in the summer of 2010. The four day, residential workshop has a 
long history of successes. The workshops are held in eastern Oregon at Lake Creek Camp, approximately 20 miles east of Seneca, Oregon.

\section{Objectives and Expected Outcomes}

According to the Teacher Education Specialist/Creeks and Kids Workshop Coordinator, after exposure to the instruction, curricula, fieldwork experiences and community partnerships introduced during Creeks and Kids, participants are able to:

1. Understand the function and importance of watersheds to ecosystem health, and the requirements for healthy fish and wildlife.

2. List ways in which they can contribute to watershed health, monitoring, and restoration.

3. Function as a member of a team to conduct watershed surveys and relate the data to watershed health and restoration.

4. Conduct watershed restoration and monitoring activities in coordination with agency partners, make the community aware of their work, and the reasons the work is important.

5. Compare watershed data over time to identify healthy and sub-healthy watersheds, and propose strategies with agency partners for improvement.

6. Discuss the role each citizen plays in watershed stewardship .

7. Recognize artistic, cultural, economic, and scientific connections healthy streams and watersheds have on the community.

8. Empower educators with enough knowledge and confidence to present and deliver topics to students so the material becomes used rather than stored on the shelf.

\section{Objectives:}

Creeks and Kids Workshops have many benefits to recreational or commercial 
fisheries.

1) Workshop participants, and subsequently their students and peers from throughout the state, work cooperatively with ODFW staff to collect much needed accurate water quality stream data.

2) Workshop participants become engaged in on-the-ground watershed monitoring and restoration projects, working side-by-side with agency staff.

3) Workshop participants become a highly trained and passionate group that positively affects the habitat and health of fisheries.

4) Workshop participants learn first-hand stream monitoring and enhancement techniques from ODFW staff using "The Stream Scene" curriculum, developed with ODFW fish and wildlife professionals.

5) The Creeks and Kids program works to create an informed citizenry who have the ability to make informed decisions about the future health of our streams and rivers.

For 20 years, over 1,000 people have participated in the Creeks and Kids program. Many of these people have worked with STEP biologists from ODFW and other fish and wildlife professionals to improve stream health in the state. The projects that participants get involved in are diverse, from stream and wetland enhancement partnerships, stream mapping and monitoring, to organizing public events that celebrate the importance of fish and wildlife habitat.

\section{Fishery Benefits:}

The future health of watersheds and fish and wildlife habitat in Oregon is the primary goal of the Creeks and Kids program. The format is to connect formal and nonformal educators, and ultimately their students, with authentic involvement and learning opportunities in their local watersheds. Educators gain the knowledge, skills, and confidence to use streams, riparian areas and watersheds as science learning sites, and many also conduct monitoring and restoration projects under the direction of ODFW staff and other agency staff involved in watershed health. 
In particular, the partnership the participants formed with the STEP biologists has been extremely valuable to ensuring high quality scientific and technically accurate stream monitoring and enhancement. The Creeks and Kids program strategy has worked very successfully for 20 years, resulting in activities in and about watersheds by schools, non-profit groups, other agencies, and students across the state. Many participating school teachers have changed their science curriculum to include watershed education and involvement because of their experiences with Creeks and Kids. ODFW's commitment to the program for all these years has helped broaden the involvement of other agencies that have a similar vision for the health of Oregon's watersheds. This broad-based collaboration and interest in the Creeks and Kids program has helped tremendously to increase watershed literacy and involvement in Oregon.

\section{Inventory of Materials Provided by Creeks and Kids Workshop}

Below is a list of what teacher-participants receive as a result of paying the $\$ 35$ workshop fee for the week:

1. Lodging for 5 days at the Lake Creek Camp outside of Seneca, Oregon.

2. Three meals a day plus snacks and drinks provided throughout the day between meals.

3. Copies of Project WET, Project WILD Aquatic and The Stream Scene curricula.

4. Complete access to all gear needed for field study and activities (e.g., hip waders, data collection equipment such as water quality instruments).

5. Macroinvertebrates identification toolkit and supplies to take home.

6. "Down to the Sea The story of the little salmon and his neighborhood", a book about the Oregon Plan for Salmon and Watersheds by Jay W. Nicholas.

7. Aquatic Resources Education Curriculum from the Future Fisherman Foundation and American Sport fishing Association.

8. Healthy Waters "Kids" education magazine and activity book. 
9. The Oregon Plan 2007-2009 Biennial Report for Salmon and Watersheds.

10. “An Educator's Resource Guide for Hatching Salmon and Trout in the Classroom" by the Oregon Department of Fish and Wildlife Salmon-Trout Enhancement Program.

11. Raffle prizes (1 per participant, randomly drawn): Macroinvertebrate identification books, additional watershed and water-focused curricula and books, assorted field guides (bird identification, plants and wildlife, etc.), macroinvertebrates sampling equipment such as D-nets, assorted gift certificates.

12. Certificate of completion of the workshop and recognition for contributions during the week.

13. Participants take home products from activities during the week (e.g., stream depth measurement sticks, topographic maps, etc.).

\section{Sample Creeks and Kids Workshop Schedule of Activities/Syllabus for 2009}

\section{Monday July 20}

4:30 Travel to Strawberry watersheds for overview

6:00 Dinner

6:45 Land or Water (globe throw activity)

7:30 Oregon Plan

8:15 Logistics, sleeping quarters, social time

8:25 Construction of the Creeks and Kids 2009 Rock hopper Special

\section{$\underline{\text { Tuesday July } 21}$}


7:00 Breakfast

8:00 Six-bits activity

8:30 Who we are and what we are about

8:45 What is a Watershed? A Sense of Place: Stream Scene, including the drainage basin activities in the Stream Scene)

9:45 Break

10:00 Stream Scene Overview

10:30 Constructing a Watershed-AQUATIC WILD

11:00 Field Investigations Overview and Field Site Orientation

- Mapping

- Water quality

- Fish sampling

- Wildlife inventory

12:15 Lunch

1:15 Build a Bug from Stream Scene

2:45 Break

3:00 Hooks and Ladders

3:45 Macro invertebrates

4:30 Macro invertebrates Mayhem

5:00 VB, Horseshoes, free time 
6:00 Dinner

7:00 Why the Crayfish Has His Eyes on Stalks

8:30 Social hour and Evening Nature option

\section{Wednesday July 22}

7:00 Breakfast

8:00 Station Orientation

8:30 Stations-Rotation 1

9:35 Stations-Rotation 2

10:40 Stations-Rotation 3

11:45 Lunch

12:45 Stations-Rotation 4

1:50 Stations-Rotation 5

3:15 Project Aquatic WILD

- Overview

- Dragonfly Pond

4:00 Break

4:15 What a Relief activity

6:00 Dinner

7:15 Project WET 
- Overview

- Incredible Journey

8:15 Data Collection Sign-up

8:30 Social hour and bookbinding

\section{Thursday July 23}

7:00 Breakfast

8:00 Data Collection

11:00 Meet as data collection groups with station staff member

11:45 Lunch

1:00 Prepare "Coming Home" presentations

4:45 Fish Eggs to Fry and Luck of the Draw activities

6:00 Dinner

7:00 Fish Dissection activity

8:30 Social hour

\section{Friday July 24}

7:00 Breakfast

8:00 "Coming Home" presentations

9:00 Stream Scene curriculum in an elementary system 
9:30 Break

9:45 Special presentation and group pictures

10:30 TBA

11:15 Certificates and Evaluations

11:30 Lunch

12:00 Clean up, pack and go! 


\section{Appendix C: Qualitative Interview Forms, Protocols and Coding Description}

\section{Teacher-participant Interview Form}

1. Primary motivations for attending the workshop?

2. What aspects of the workshop were most satisfying?

3. What aspects of the workshop were most challenging or frustrating?

4. Did you have any anticipated outcomes regarding your participation in the workshop?

5. Did the workshop experience encourage you to reflect on your current teaching strategies and approaches to environmental education and/or science education?

6. Were there any topics in Creeks and Kids that caused you anxiety or uncertainty based on your previous knowledge, skill level or experience with the topics? Which topics?

7. Do you anticipate that any teaching approaches/strategies will change as a result of your participation in the workshop?

8. Will you/have you share(d) your Creeks and Kids experience with colleagues?

9. What is your perception of the Creeks and Kids instructor team?

10. Anything else that you would like to add or comment? 


\section{Instructor Interview Form}

1. How long have you been with Creeks and Kids, and how did you get involved?

2. What do you want participants to take away from the workshop?

3. How do you assess for understanding/engagement, and is this difficult to do in this setting?

4. What other workshops have you attended and how they are similar/different than Creeks and Kids?

5. Why do you keep coming back to teach at Creeks and Kids?

6. What kind of support do you get from other staff, is there anything unique about it?

7. Do you have any advice that you would offer to other professional development programs based on your Creeks and Kids experience? 


\section{Interview and Observation Protocols}

\section{Interview Protocol}

\section{Time of interview:}

Date:

Place:

Interviewer: Tiffany Austin

Interviewee: (confidential participant-selected code; i.e. favorite book and favorite color) "Code \# ex: A129"

Position of interviewee: 2009 Creeks and Kids participant

Description to interviewee: You have been invited to participate in this research study because you have been or will be involved in the Creeks and Kids workshop presented by Jackson Bottom Wetlands Preserve in partnership with Portland State University. The purpose of this research study is: (1) to learn the impacts of the Creeks and Kids workshop on educators' knowledge of, skills for and attitudes about stream and watershed environmental education; (2) to find out how educators' plan to implement or have implemented what they've learned from the Workshop, including curriculum and teaching strategies, into their classrooms or educational setting; and (3) to find out the realities and challenges to implementation of the curriculum in these settings.

I would like to ask you some questions regarding your involvement as a participant in the Creeks and Kids Workshop. These questions will be about what you learned during the Workshop, what you liked about it most/least, any breakthrough moments for you during the Workshop or later on, and how you plan to or already implement elements of 
what you learned in the Workshop in your classroom/educational setting including any anticipated or real challenges to implementation.

Your name is not connected in any way to this form or to anything that will be written up about this interview session. You will remain as an anonymous interviewee with a subject number so that I can keep different interview forms separate for my analysis of the data. Any of the information collected during this interview will be kept in a secure and locked cabinet in Room 101 of Epler Hall in Portland State University's Center for Science Education and will be destroyed in six years in December 2015.

This interview will take approximately 30-45 minutes. This interview may be recorded, with your consent only, so that I can go back to parts of the interview during my analysis. You will in no way be identified on any recordings with your name. You will only be referred to as the code you have chosen that you will remember, i.e. your favorite book and your favorite color (ex: "Pride and Prejudice" "Purple").

You have the right to refuse to answer any of the questions I ask you during this interview. You have the right to completely refuse to be interviewed and/or to refuse that the interview be recorded. There will be no penalty or loss of any benefits to which you are otherwise entitled if you refuse the interview or to answer any questions, and it will in no way compromise your relationship with Jackson Bottom Wetlands Preserve or Portland State University. If you agree to participate in this interview, please say "I agree to participate in the interview" (if it is a phone interview-subject will have already signed an informed consent form to participate in the study itself). Thank you in advance for your time and participation.

Questions:

1. Primary motivations for attending the workshop?

2. What aspects of the workshop were most satisfying?

3. What aspects of the workshop were most challenging or frustrating? 
4. Did you have any anticipated outcomes regarding your participation in the workshop?

5. Did the workshop experience encourage you to reflect on your current teaching strategies and approaches to environmental education and/or science education?

6. Were there any topics in Creeks and Kids that caused you anxiety or uncertainty based on your previous knowledge, skill level or experience with the topics? Which topics?

7. Do you anticipate that any teaching approaches/strategies will change as a result of your participation in the workshop?

8. Will you/have you share(d) your Creeks and Kids experience with colleagues?

9. What is your perception of the Creeks and Kids instructor team?

10. Anything else that you would like to add or comment? 


\section{Observation Protocol Example}

Observational Field Notes: Creeks and Kids Workshop 2009

Setting: (example) Macro invertebrates field activities

Observer: Tiffany Austin

Role of observer: Observer of participant interactions with water sampling tools

Time: (example) 3:00pm, July 21, 2009

Length of observation: 25 minutes

Description of Interaction:

Reflective Notes: 


\section{Qualitative Coding of Participant Interviews}

Qualitative analysis methodology was adapted from the Connolly model that involves an initial phase to conduct analysis of the data sentence-by-sentence and wordby-word for recurring words and phrases. Lists of meaning and coded notes from the initial phase were used to develop themes from the coded notes (Connolly, 2003, as cited in Austin et. al, 2009). The themes were translated into conceptual categories, thus, the process involved movement from data to themes and from themes to conceptual categories to provide connections among the themes.

\section{Section 1: Qualitative Data from Teacher-participant Interviews}

\section{1a: What was your primary motivation for participating in the Creeks and Kids Workshop? (Q\#1)}

a. Thinking of ways to adapt environmental education aspects to a new grade level curriculum

b. Wanted to have fun

c. Low cost

d. Was referred during a class at Portland State

e. Workshop leader's description sounded fun and interesting

f. Workshop seemed to align with my current curriculum goals

g. Wanted to be more comfortable with doing inquiry lessons with students outside

h. Learn different ways of presenting material to students

i. Get away from lecture style of teaching 
j. Be exposed to different ways of delivery

\section{1b: What aspects of the workshop were most satisfying? (Q\#2)}
a. Hands-on activities
b. Feasibility of doing activities with students
c. Classroom activities demonstrated well
d. Hands-on
e. Being in the creek
f. Doing the activities
g. Challenges made me think of how to approach challenges in a classroom
h. That it's normal and OK to be frustrated
i. Love that workshop!
j. Practical ways to instantly integrate into the classroom without having to stretch
k. Fieldwork
1. Field activities and setup was extraordinary
m. Classroom lesson were essential
n. Getting comfortable to bring kids to the water!
o. Loved the water activities
p. Macro invertebrate activities
q. Fish surveying
r. Love being in the water
s. Hands-on, not just all classroom
t. Being outside and doing the activities 


\section{1c: What aspects of the workshop were challenging and/or frustrating? $(Q \# 3)$}

a. Other personalities during the group work

b. Difficulty to engage with group members

c. When frustration came up, realized it's OK to be frustrated and challenged

d. Seemed like the crux of the Workshop was geared towards middle to high school; should be more modifications for primary

e. Working with fellow teachers

f. Workshop leader's comment (presenting to peers)

g. More field activities, less classroom time

h. Group activities with other teachers

i. Having to react and deal with different personalities instead of working on activities

j. Made me think of my kids in school having to work in groups 
1d: Did you have any anticipated outcomes prior to attending the Creeks and Kids workshop? (Q\#4)

a. Didn't even know what a watershed was, so no

b. It is hard to get a workshop with a field experience, so my expectations were high

1e: What were the actual outcomes you perceived after attending the Creeks and Kids workshop? (Q\#5)

a. Energized and excited to teach kids about what I learned

b. Wanted to spread the enthusiasm

c. Water is a worthwhile topic to get kids engaged in and learning about

d. Water fits into any curriculum

e. All expectations were met and exceeded (012)

f. Took away so much more than expected

g. Definitely helped me to feel more comfortable on how you have students put this EE into action

h. Inspired me to start an afterschool club to focus on just environmental issues

i. Can use water as a theme throughout different strands, as long as I get the benchmarks in there 
1f: Did Creeks and Kids encourage you to reflect on current teaching strategies or approaches to environmental education and/or science education? (Q\#6)

a. Affirmed that hands-on activities are good for students

b. Used to think I had to stick strictly to the textbook, can still teach to curriculum and bring EE into the classroom

c. Creating themes around water

d. Reaffirms my team teaching strategies

e. Teachers teaching teachers is important

f. The graduate credit assignment that forced me to sit down and reflect right away was valuable; had to figure out how to apply lessons and activities

g. Practical applications

1g:Were there any workshop topics that caused anxiety or uncertainty? $(\mathrm{Q} \# 7)$

a. Didn't know what a watershed was, so first day activity driving up to vista point to see watershed made things clear

b. None

c. None

d. The last presentation as a group; but learned about group dynamics more and put me in the students' shoes

e. It's hard to have another person's perspective unless you experience it, helps me to have a better understanding of my students

1h:Did you share your Creeks \& Kids experience with any colleagues? (Q\#8) 
a. Can't wait to get DVD to talk it up and get more people to go next year

b. Shared my Stream Scene books

c. Told 4 teachers who I thought would be receptive

d. Gave my Stream Scene to a teacher who wasn't able to go to the Workshop

e. Trying to get my teaching partner to go next year, we do World Water Monitoring Day together

f. Emailed the school and told them it's wonderful

g. Shared with 3 different districts in addition to a writing project we're involved in

1i: What was your perception of the Creeks and Kids instructor team? (Q\#9)

a. Absolutely wonderful, all of them

b. Left me to my own inquiry

c. Good to let students get thrown in and "swim around" a bit on their own

d. Well-rounded experience, all of them good

e. They were all amazing, each one knew their subject really well

f. Their excitement level is what I aspire to be when I teach every class

g. I just thought they were great

h. Particularly could relate to the instructor who was a classroom teacher and easily showed us how to integrate

i. Learned that I could contact JBWP when needed - that is rare, usually after a workshop is done, that's it

j. Good ideas and helpful teaching strategies (001)

k. Classroom management techniques such as "Deer Ears" and "Owl Eyes" (001) 
1. Using the theme of water for a lesson, unit or entire school year (001), (014)

m. Instructors from Creeks \& Kids supportive, gave a lot of positive reinforcement (001)

\section{1j: Do you have anything else you would like to add? (Q\#10)}

a. Creeks and Kids activities helping my students gain an understanding of their responsibility to be stewards of the habitat around them (014)

b. Creeks and Kids helped me learn about STEP grants and grants in general, so can get more involved

c. Workshop special because of uniqueness: a lot of workshops talk about handson while you are sitting in a seat and taking notes. At Creeks and Kids we were out there doing it

d. True modeling and really doing what you'll be teaching

e. Not just telling you or talking at you

f. I've not been to any other workshops that have encouraged me to contact them after, once they're (the other workshops) done, that's it

g. Creeks and Kids truly gave an invitation, gives me more courage and if I have questions I have someone I can call

h. Staff makes themselves available for after-the-fact questions

i. I had a great time!!

j. Unique in that it focuses on outside, but shows you both ways to see curriculum potential if you can't get outside 


\section{Appendix D: Creeks and Kids Pre-Post Questionnaire}

\section{Creeks and Kids}

\section{Participating Educator Information Form}

\section{SECTION I: Background Information}

Name:

Date you completed this survey:

Year(s) participated in

Creeks \& Kids Workshop:

1. How you found out about the Creeks \& Kids

Workshop:

Please provide the following background information if applicable, write N/A if not applicable:

2. Teaching Licensure (Please indicate the state(s) where you are licensed to teach):

3. Teaching Certificate(s) (Please identify each professional teaching certificate you have earned):

Early/Elementary:

Middle Grades:

Secondary:

Other: 
4. Endorsements (Please identify each endorsement you have earned):

5. Total number of years teaching science subjects (Please indicate what subjects in science, i.e. biology, physics, and the corresponding years you've taught the subject(s)):

6. Number of years teaching environmental education (EE) subjects (Please indicate names of EE subjects and the corresponding years you have taught them):

7. Grades taught in the past (Please indicate which grades you have taught in the past and what subjects): 
8. Grades you teach currently (Please indicate which grades you teach now and what subjects):

9. Type of educational facility/setting where you teach (Please check all that apply. Write in "other" area if your facility or setting is not listed)

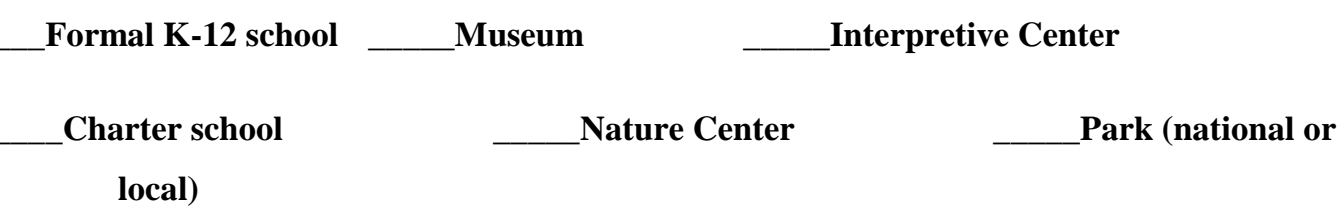

4-year University ___Less than 4-year/community college

Alternative school (please explain type below)

Environmental Education Center (please explain type below)

Other (please explain below) 
10. Higher Education Degrees Earned

Please check each degree you have earned (left column), and identify the area(s) in which you have earned each degree (right column).

_ Bachelors, Area(s):

__ Masters, Area(s):

Masters + 30, Area:

Specialist, Area:

Doctorate, Area:

Other (ID Type \& Area of Degree):

Environmental Education Coursework \& Professional Development

11. Identify and briefly describe any specific environmental education coursework you took that influences your current teaching and where you took the course

(Please indicate the course that was at or through a college or university, and how it has influenced your teaching, i.e. you still use teaching strategies and/or curriculum materials when you teach, leave blank if not applicable):

*

12. Identify and briefly describe any environmental education professional development experience(s) you have had that influences your current teaching 
(Please indicate the type of professional development, such as workshops, lesson study and/or seminars, and how it has influenced your teaching, i.e. you share what you learned with others or still use teaching strategies and/or curriculum materials when you teach, leave blank if not applicable):

$*$

$*$

$*$

13. How many of those environmental education professional development opportunities fit each time period (length) below

(Please indicate with the number of opportunities for each category, leave blank if it not applicable):

less than a full day between 3-7 days

between 1-2 days longer than a week

Item 14: Gender (Please indicate gender by marking with an $X$ ):

__Female __ Male

Item 15: Age Group (Please indicate age group by marking with an X):

_ under $21 \_$_21-30 _ 31-40_41-50_ 51-60_ over 60

Item 16: Ethnic/Racial Background (Please indicate the best response with an $X$, you may leave blank if you do not want to answer):

American Indian/Alaskan Native

__ Asian/Pacific Islander 
Hispanic

__ Black (non Hispanic)

_ White (non Hispanic)

__ Bi-ethnic/biracial (any two of the above)

__ Multiethnic/multiracial (more than two of the above)

\section{Views on Environmental Education (EE)}

(Circle the number that best reflects your thoughts/feelings)

17. How important is it that K-12 students have EE in their curriculum?

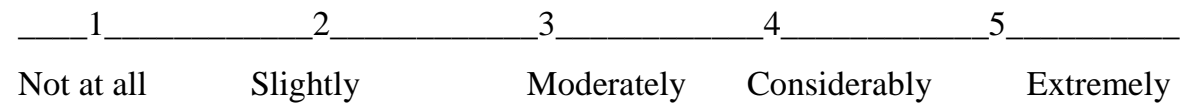

18. How important is EE to you personally?

\begin{tabular}{|c|c|c|c|c|}
\hline 1 & 2 & 3 & 4 & 5 \\
\hline
\end{tabular}

\section{Environmental Education (EE)}

(Circle the number that best reflects your thoughts/feelings)

19. How interested are you to incorporate EE into your curriculum?

\begin{tabular}{|c|c|c|c|c|}
\hline 1 & 2 & 3 & 4 & 5 \\
\hline
\end{tabular}


20. How concerned are you about the health of streams and watersheds?

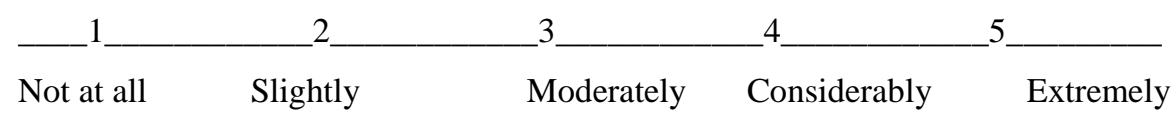

21. How important do you think it is to involve your students or community in environmental education service learning?

\begin{tabular}{|c|c|c|c|c|}
\hline 1 & 2 & 3 & 4 & 5 \\
\hline
\end{tabular}




\section{Creeks and Kids Workshop Survey Form}

Answer to the best of your ability without the aid of a resource such as a reference book or computer

Please make brief lists to answer the questions below:

22. List 2-3 functions of watersheds that are important for ecosystem health, fish and wildlife, community health, and the planet

23. List 2-3 ways in which you think you can contribute to watershed health and restoration

24. List 3 ways that you could conduct watershed restoration activities 
25. List 2-3ways you could make your community aware of your watershed restoration work

26. List 3 reasons why you think watershed restoration work is important 
2) Please indicate your knowledge of (Check ONLY ONE answer per statement):

\begin{tabular}{|c|l|l|l|l|l|}
\hline & None & Little & Some & Moderate & Considerable \\
\hline $\begin{array}{c}\text { 27. Aquatic } \\
\text { organisms }\end{array}$ & & & & & \\
\hline $\begin{array}{c}\text { 28. Macro- } \\
\text { invertebrates }\end{array}$ & & & & & \\
\hline $\begin{array}{c}\text { 29. Relationships } \\
\text { among } \\
\text { precipitation, } \\
\text { runoff, and } \\
\text { aquatic habitats }\end{array}$ & & & & & \\
\hline $\begin{array}{c}\text { 30. Salmon Life } \\
\text { Cycle }\end{array}$ & & & & & \\
\hline $\begin{array}{c}\text { 31. Human } \\
\text { impacts to streams } \\
\text { and watersheds }\end{array}$ & & & & & \\
\hline
\end{tabular}




\begin{tabular}{|c|l|l|l|l|l|}
\hline & None & Little & Some & Moderate & Considerable \\
\hline $\begin{array}{c}\text { 32. The movement } \\
\text { of water within } \\
\text { the water cycle }\end{array}$ & & & & & \\
\hline $\begin{array}{c}\text { 33. The states of } \\
\text { water as it moves } \\
\text { through the water } \\
\text { cycle }\end{array}$ & & & & & \\
\hline $\begin{array}{c}\text { 34. Strategies to } \\
\text { assess the health } \\
\text { of a stream }\end{array}$ & & & & & \\
\hline $\begin{array}{c}\text { 35. Topography } \\
\end{array}$
\end{tabular}

3) Please indicate your knowledge of or experience with the following (Check ONLY ONE answer per statement):

\begin{tabular}{|c|l|l|l|l|l|}
\hline & None & Little & Some & Moderate & Considerable \\
\hline $\begin{array}{c}\text { 36. Wildlife inventory } \\
\text { 37. Water Quality } \\
\text { testing }\end{array}$ & & & & & \\
\hline
\end{tabular}




\begin{tabular}{|c|l|l|l|l|l|}
\hline $\begin{array}{c}\text { 38. Data collection in } \\
\text { the field }\end{array}$ & & & & & \\
\hline $\begin{array}{c}\text { 39. Measuring and } \\
\text { calculating the area } \\
\text { of a field study site }\end{array}$ & & & & & \\
\hline $\begin{array}{c}\text { 40. Calculating the } \\
\text { volume and weight of } \\
\text { water falling on a } \\
\text { field study site }\end{array}$ & & & & & \\
\hline $\begin{array}{c}\text { 41. Determining } \\
\text { specific and annual } \\
\text { rainfall and runoff }\end{array}$ & & & & & \\
\hline $\begin{array}{c}\text { 42. Tracing the } \\
\text { course of water to } \\
\text { aquatic habitats }\end{array}$ & & & & & \\
\hline
\end{tabular}




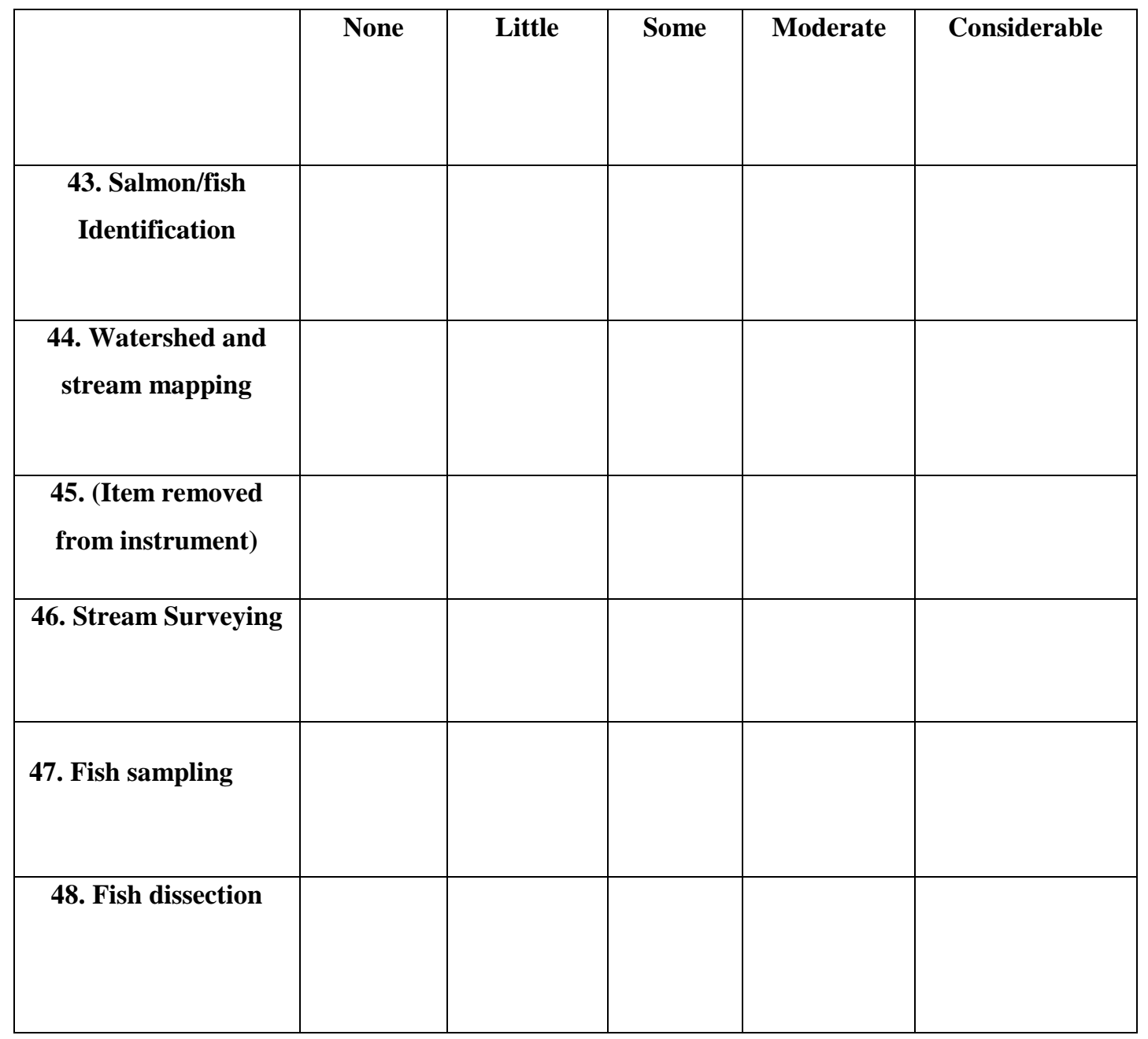


1) Please indicate how often in your teaching practice you (Check ONLY ONE answer per statement):

\begin{tabular}{|l|l|l|l|l|l|}
\hline & None & Little & Some & Moderate & Considerable \\
\hline $\begin{array}{l}\text { Encourage the } \\
\text { process of scientific } \\
\text { inquiry }\end{array}$ & & & & & \\
\hline $\begin{array}{l}\text { Engage students in } \\
\text { environmental } \\
\text { education } \\
\text { curriculum and/or } \\
\text { activities }\end{array}$ & & & & & \\
\hline $\begin{array}{l}\text { Let students guide } \\
\text { discussions }\end{array}$ & & & & & \\
\hline $\begin{array}{l}\text { Allow students to } \\
\text { conduct their own } \\
\text { experiments }\end{array}$ & & & & & \\
\hline $\begin{array}{l}\text { Have students use } \\
\text { science equipment } \\
\text { or tools to collect } \\
\text { data } \\
\text { outdoor } \\
\text { education lessons }\end{array}$ & & & & & \\
\hline $\begin{array}{l}\text { Engage students in } \\
\text { andronmental }\end{array}$ & & & & \\
\hline
\end{tabular}


6) Please check ONLY ONE answer for each statement:

\begin{tabular}{|c|c|c|c|c|c|}
\hline & $\begin{array}{l}\text { Strongly } \\
\text { Disagree }\end{array}$ & Disagree & Neutral & Agree & $\begin{array}{l}\text { Strongly } \\
\text { Agree }\end{array}$ \\
\hline $\begin{array}{l}\text { 54. The health of the } \\
\text { watershed in which I live } \\
\text { is connected to my own } \\
\text { health }\end{array}$ & & & & & \\
\hline $\begin{array}{l}\text { 55. It is easy to tell if a } \\
\text { stream is healthy }\end{array}$ & & & & & \\
\hline $\begin{array}{l}56 . \text { It is important to } \\
\text { engage in activities and } \\
\text { events that aim to } \\
\text { spread environmental } \\
\text { awareness }\end{array}$ & & & & & \\
\hline $\begin{array}{l}57 . \text { It is important to } \\
\text { have a lot of vegetation } \\
\text { along the banks of a } \\
\text { stream }\end{array}$ & & & & & \\
\hline $\begin{array}{l}58 . \text { Human-made dams } \\
\text { can impact a river } \\
\text { system }\end{array}$ & & & & & \\
\hline $\begin{array}{l}\text { 59. Insects are important } \\
\text { to the health of a stream } \\
\text { or river system }\end{array}$ & & & & & \\
\hline
\end{tabular}




\begin{tabular}{|l|l|l|l|l|l|}
\hline & $\begin{array}{l}\text { Strongly } \\
\text { Disagree }\end{array}$ & Disagree & Neutral & Agree & $\begin{array}{l}\text { Strongly } \\
\text { Agree }\end{array}$ \\
\hline $\begin{array}{l}\text { 60. It is my personal } \\
\text { responsibility to help } \\
\text { protect natural areas } \\
\text { such as streams and } \\
\text { rivers. }\end{array}$ & & & & & \\
\hline $\begin{array}{l}\text { 61. I think that it is } \\
\text { important to participate } \\
\text { in public service to } \\
\text { protect the natural } \\
\text { resources where I live. }\end{array}$ & & & & & \\
\hline $\begin{array}{l}\text { 62. It is important that } \\
\text { the vegetation along a } \\
\text { stream is native to that } \\
\text { area }\end{array}$ & & & & & \\
\hline
\end{tabular}




\begin{tabular}{|c|c|c|c|c|c|}
\hline & $\begin{array}{l}\text { Strongly } \\
\text { Disagree }\end{array}$ & Disagree & Neutral & Agree & $\begin{array}{l}\text { Strongly } \\
\text { Agree }\end{array}$ \\
\hline $\begin{array}{l}\text { 63. I feel qualified to } \\
\text { compare watershed data } \\
\text { over time to identify } \\
\text { healthy and sub-healthy } \\
\text { watersheds }\end{array}$ & & & & & \\
\hline $\begin{array}{l}\text { 64. It is important that } \\
\text { the fish that are in a } \\
\text { stream are native to that } \\
\text { stream }\end{array}$ & & & & & \\
\hline $\begin{array}{l}\text { 65. I feel that I am } \\
\text { currently able to propose } \\
2-3 \text { strategies to improve } \\
\text { the health of sub-healthy } \\
\text { watersheds }\end{array}$ & & & & & \\
\hline $\begin{array}{l}66 . \text { I feel that I would be } \\
\text { able to contribute as a } \\
\text { member of a team to } \\
\text { conduct watershed } \\
\text { surveys }\end{array}$ & & & & & \\
\hline $\begin{array}{l}67 . \text { I am able to discuss } \\
\text { the role that citizens play } \\
\text { in watershed stewardship }\end{array}$ & & & & & \\
\hline
\end{tabular}




\section{Appendix E: Follow Up Form}

Name:

Date:

1. How many different activities (from Stream Scene, Project WET and Project WILD Aquatic) have you used since taking the Creeks and Kids Workshop and in what classes/activities?

2. What other activities from the three curricula (Stream Scene, Project WET, and Project WILD Aquatic) that were not introduced to you during the Creeks and Kids Workshop have you sought out? How many have you implemented?

3. Please describe how you have adapted the Creeks and Kids curriculum in your classroom/educational setting over time: (e.g. how, if at all, has your use of the curriculum changed or evolved):

4. Briefly describe the specific ways, if any, in which the Creeks and Kids Workshop has impacted the way that you incorporate environmental education into your educational setting (i.e. your confidence to implement, methods and strategies, etc.):

5. In what ways, if at all, has your participation in the Creeks and Kids Workshop influenced your perceptions about the importance to integrate environmental education (EE) into your educational setting? (if you already incorporate EE, has Creeks \& Kids changed how you do this or think about doing this?)

6. How, if at all, has your participation in the Creeks and Kids Workshop influenced your teaching practice regarding a person's environmental behaviors and/or attitudes ? (e.g. do you engage students in discussions about behaviors and attitudes relating to the environment or watersheds?)

7. Please indicate with whom you have shared your experience with the Creeks and Kids Workshop.

Department Chair or Grade Chair

Teacher(s) within my department. Please indicate how many here: 
Teacher(s) in other departments in my school. Please indicate how many and in what departments here:

Teacher(s) in other schools. Please indicate how many different schools here:

Other/non-formal educational settings (please specify on lines below)

(Other)

8. Please indicate with whom you have shared curriculum materials from the Creeks and Kids Workshop.

Department Chair or Grade Chair

Teacher(s) within my department. Please indicate how many here:

$\square$ Teacher(s) in other departments in my school. Please indicate how many and in what departments here:

Teacher(s) in other schools. Please indicate how many different schools here:

Other/non-formal educational settings (please specify on lines below)

(Other) 


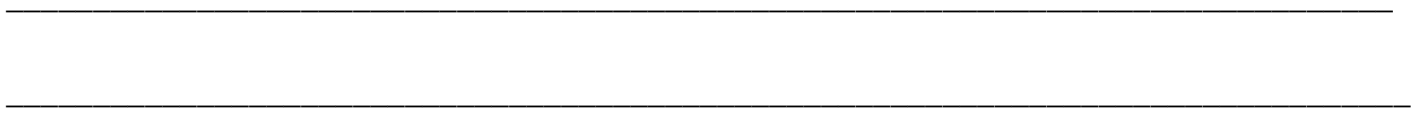




\section{Appendix F: Creeks and Kids History and Grant Proposal}

\section{Activity Type: Education}

"Creeks and Kids" is a four day, time-tested, field based workshop for natural resource specialists, teachers, and individuals interested in aquatic-watershed education and involvement programs. Each year, 30 participants work with ODFW, Jackson Bottom Wetlands, and other agency staff to gain skills in getting students involved in watershed education and restoration work.

\section{Summary:}

Project \#: 09-152

Creeks and Kids Watershed Workshops

Last Modified/Revised: 9/25/2009 2:31:10 PM Page 1 of 13

ODFW and Jackson Bottom Wetlands Preserve partnered to continue the 20 year history of providing this program. It can truthfully be said that the majority of school activities in Oregon centered on watersheds and salmon had its beginnings in Creeks and Kids workshops.

The overall goal of the Creeks and Kids program is to increase citizen involvement in improving salmon and trout populations, improving water quality, and restoring watershed function, resulting in healthy watersheds throughout Oregon. Funding from ODFW R\&E will allow 30 participants per year including classroom teachers, museum educators, natural resource specialists, and agency staff to participate in Creeks and Kids in the summer of 2010. The four day, residential workshop has a long history of successes. The workshops are held in eastern Oregon at Lake Creek Camp, approximately 20 miles east of Seneca, Oregon.

After attending Creeks and Kids, participants are able to, through their teachers and appropriate curricula, experiences, and partnerships:

1. understand the function and importance of watersheds to ecosystem health, and the requirements for healthy fish and wildlife.

2. list ways in which they can contribute to watershed health, monitoring, and restoration.

3. function as a member of a team to conduct watershed surveys and relate the data to watershed health and restoration.

4. conduct watershed restoration and monitoring activities in coordination with agency partners, make the community aware of their work, and the reasons the work is important.

5. compare watershed data over time to identify healthy and sub-healthy watersheds, and propose strategies with agency partners for improvement. 6. discuss the role each citizen plays in watershed stewardship . 
7. recognize artistic, cultural, economic, and scientific connections healthy streams and watersheds have on the community.

8. empower educators with enough knowledge and confidence to present and deliver topics to students so the material becomes used rather than stored on the shelf.

\section{Objectives:}

Project \#: 09-152

Creeks and Kids Watershed Workshops

Last Modified/Revised: 9/25/2009 2:31:10 PM Page 2 of 13

Creeks and Kids Workshops have many benefits to recreational or commercial fisheries.

1) Workshop participants, and subsequently their students and peers from throughout the state, work cooperatively with ODFW staff to collect much needed accurate water quality stream data.

2) Workshop participants become engaged in on-the-ground watershed monitoring and restoration projects, working side-by-side with agency staff.

3) Workshop participants become a highly trained and passionate group that positively affects the habitat and health of fisheries.

4) Workshop participants learn first-hand stream monitoring and enhancement techniques from ODFW staff using "The Stream Scene" curriculum, developed with ODFW fish and wildlife professionals.

5) The Creeks and Kids program works to create an informed citizenry who have the ability to make informed decisions about the future health of our streams and rivers.

For 20 years, over 1,000 people have participated in the Creeks and Kids program. Many of these people have worked with STEP biologists from ODFW and other fish and wildlife professionals to improve stream health in the state. The projects that participants get involved in are diverse, from stream and wetland enhancement partnerships, stream mapping and monitoring, to organizing public events that celebrate the importance of fish and wildlife habitat.

\section{Fishery \\ Benefits:}

Project \#: 09-152

Creeks and Kids Watershed Workshops

Last Modified/Revised: 9/25/2009 2:31:10 PM Page 3 of 13

The future health of watersheds and fish and wildlife habitat in Oregon is the primary goal of the Creeks and Kids program. The format is to connect formal and nonformal educators, and ultimately their students, with authentic involvement and learning opportunities in their local watersheds. Educators gain the knowledge, skills, and confidence to use streams, riparian areas and watersheds as science learning sites, and many also conduct monitoring and restoration projects under the direction of ODFW staff and other agency staff involved in watershed health. 
In particularly the partnership the participants formed with the STEP biologists has been extremely valuable to ensuring high quality scientific and technically accurate stream monitoring and enhancement.

The Creeks and Kids program strategy has worked very successfully for 20 years, resulting in activities in and about watersheds by schools, non-profit groups, other agencies, and students across the state. Many participating school teachers have changed their science curriculum to include watershed education and involvement because of their experiences with Creeks and Kids. ODFW's commitment to the program for all these years has helped broaden the involvement of other agencies that have a similar vision for the health of Oregon's watersheds. This broad-based collaboration and interest in the Creeks and Kids program has helped tremendously to increase watershed literacy and involvement in Oregon.

\section{Watershed \\ Benefits:}

Project \#: 09-152

Creeks and Kids Watershed Workshops

Last Modified/Revised: 9/25/2009 2:31:10 PM Page 4 of 13

Creeks and Kids have been offered regularly every summer for most of its long history. ODFW R \& E has funded Creeks \& Kids for the summers of 07, 08 and 09. This proposal is aimed at securing funding for the program for the summer of 2010. In the late 1990's, when (anonymous) was contemplating retiring from ODFW, she had asked if Jackson Bottom Wetlands Preserve would take on the coordination of the Creeks and Kids program. S/he was instrumental in its development and implementation, and is still involved with the program every summer as a volunteer. S/he wanted to make sure the program continued and thrived. Since his/her retirement, Jackson Bottom Wetlands Preserve has had the opportunity to carry the program forward.

Today, (anonymous), the Jackson Bottom Teacher Education Specialist, is the coordinator for Creeks and Kids. The program continues to be very popular and meets the needs of today's watershed issues. Every year, we have people on the waiting list who want to participate. This is a high priority program for Jackson Bottom Wetlands Preserve. The Preserve is a 725 acre wetland in Hillsboro, Oregon whose mission is "Connecting Water, Wildlife, and People." One of the Preserves primary functions is to provide aquatic and watershed education programs for Oregon educators. The Preserve has been able to offer Creeks and Kids every summer since (anonymous's) retirement with support from agencies such as OWEB and ODFW. For the last few years, OWEB was very supportive and had funded the program, but due to changes in their budget, and how their funds are allocated, non-capital monies are very restrictive. We do not want to see Creeks and Kids disappear. It is too valuable of a program for Oregon's watersheds, the partners, and the participants. The Creeks and Kids Workshops in 2000 and 2001 were primarily funded by OWEB, with assistance from 
Oregon State University Sea Grant in 2000. Workshops for 2005 and 2006 were also funded by OWEB with a portion of in-kind provided by several other agencies. With $\$ 15,000$ to fund the program for 2010 we will be able to continue this successful program into the future.

One of our concerns is that funding for Creeks and Kids was very stable for well over a decade, but due to changes in both state and federal budgets, it has recently become a year-to-year funded program. This limits the ability to provide good follow up and support for the participants, and the formation of long-term partnerships. This proposal is designed to establish a more consistent program funding.

Currently the workshop is held at Lake Creek Camp in eastern Oregon. The workshops have been held in other locations in the state and can be delivered almost anywhere there is a fisheries or stream. We return to Lake Creek due to the rustic accommodations, the habitat, the isolation, total immersion and the lower cost for lodging and food.

\section{Current}

Situation:

Project \#: 09-152

Creeks and Kids Watershed Workshops

Last Modified/Revised: 9/25/2009 2:31:10 PM Page 5 of 13

Funding for Creeks and Kids has become a year-to-year effort. Originally OWEB had the program as part of their line-item budget for many years, but due to federal and state funding shifts, non-capital programs such as Creeks and Kids become lower priority. It is not that OWEB does not want to fund Creeks and Kids, but funds available for these types of programs have become extremely limited. The results and successes of Creeks and Kids are clearly evident; a secure funding source is needed to allow the program to continue. There are no other funds available for the 2010 program. All those who have been involved in Creeks and Kids would be very disappointed to see a program that actually gets work done on the ground be eliminated because of a funding issue.

\section{Alternatives:}

Creeks \& Kids was designed by ODFW staff, other agency staff, teachers, and fish and wildlife experts. Many of the same people are still involved including (anonymous and anonymous). For a full list of project partners, please see the next section.

\section{Designer:}

A variety of selected state and national curriculum is used during the program. These curriculums lay out the knowledge and skills needed for the workshop, the concept knowledge required, the educational pedagogy, and the field techniques.

In particular, Stream Scene: Watersheds, Wildlife and People has become the focal point of Creeks and Kids. Stream Scene is a publication developed by 
ODFW staff working side-by-side with profession educators, other agency staff, museum educators, and refuge staff. It was first developed in the 1980's, with the same leadership and visionary group who run the Creeks and Kids program today. It was the first watershed education curriculum tailored to the Pacific Northwest, and in its first few years of existence, became a national model. Now in its second edition, it continues to be used throughout North America, and still stands among the best available.

Since the beginnings of Stream Scene, Creeks and Kids workshops have been held to train educators in its use. Educator training workshops are known to be powerful motivators for implementing education programs in school curricula. Recent education research has shown that educators who participate in an extended program, or immersion program, have the highest record of implementing the skills and knowledge gained, back in their own community.

While Stream Scene remains the centerpiece curriculum for Creeks and Kids, Project WILD Aquatic (a supplementary curriculum formerly distributed by ODFW and published in 1983, revised several times since) and Project WET (Water Education for Teachers, a supplementary curriculum distributed through workshops and published in 1995) and others have become part of the Creeks and Kids workshop format. This has widened the appeal of Creeks and Kids to lower elementary educators and given them a strong introduction to Stream Scene and watershed education.

Another important component to Creeks and Kids is the follow up. Jackson Bottom Wetlands Preserve works to maintain communication and support with past Creeks and Kids participants. Many participants of the program return the following year.

\section{Methods:}

Project \#: 09-152

Creeks and Kids Watershed Workshops

Last Modified/Revised: 9/25/2009 2:31:10 PM Page 6 of 13

summer to learn more and fine tune their skills. Many participants have adjusted their curriculum to engage their students in watershed studies, and others have built longterm partnerships with ODFW staff, particularly the STEP biologists, to do work in the field. Assessments and program evaluations are completed at the end of each workshop. The program staff adjust the workshop to meet the needs of the watershed and the people. 


\title{
Appendix G: Human Subjects Protocols and Consent Forms
}

\author{
Portland State University \\ Consent for Creeks and Kids Study Participation
}

\begin{abstract}
TITLE: An Environment-based Education Approach to Professional Development: A Mixed Methods Analysis of the Creeks and Kids Watershed Workshop and Its Impact on K-12 Teachers
\end{abstract}

\section{PRINCIPAL INVESTIGATOR: Tiffany Austin}

SPONSOR: Center for Science Education, Portland State University

\section{PURPOSE:}

You have been invited to participate in this research study because you have been or will be involved in the Creeks and Kids workshop presented by Jackson Bottom Wetlands Preserve in partnership with Portland State University. The purpose of this research study is: (1) to learn the impacts of the Creeks and Kids workshop on educators' knowledge of, skills for and attitudes about stream and watershed environmental education; (2) to find out how educators' plan to implement or have implemented what they've learned from the Workshop, including curriculum and teaching strategies, into their classrooms or educational setting; and (3) to find out the realities and challenges to implementation of the curriculum in these settings.

If you agree to this study, you will be involved for approximately 3 months by participating in two surveys and/or one interview with Ms. Austin, a graduate student from Portland State University's Center for Science Education. The surveys will consist of one pre-test before the Workshop and one post-test following the Workshop. The interview, should you choose to agree to one, will occur in person or by phone at your convenience at a time shortly after the Workshop (within one month). 


\section{PROCEDURE:}

If you decide to participate in the study, you will be asked to complete a survey regarding your background in education, the experience you have/had with the Creeks and Kids Workshop, and how you have implemented or plan to implement the curriculum from Creeks and Kids. You will also be asked to participate in an interview after you participate in the 2009 Workshop. You may refuse to participate in any or all of these parts of the research study at any time.

\section{RISKS AND DISCOMFORTS:}

Although unlikely, it is possible that some of the questions we ask may seem personal, embarrassing or sensitive to you. You may refuse to answer any of the questions that you do not want to answer.

\section{BENEFITS:}

We hope that your participation in this study is rewarding, however you may or may not personally benefit from your experience participating in the study. However, by participating in this study, you may help us learn how to improve the Creeks and Kids workshop in the future.

\section{ALTERNATIVES:}

You may choose not to participate in this study.

\section{CONFIDENTIALITY:}

We will not use your name or any other personal information that could identify you in any way in any research papers or articles about the study.

No identifying information will appear on any of the data collection forms and information and records that we collect will be stored in locked files. Your name will be blacked out with 
permanent marker by the researcher, Ms. Austin, and your data will be given a confidential code number, such as "\# 007", so that your data will be kept confidential and separate from other participants' data during the study. Codebooks, subject identifiers and consent forms will be stored separate from the data collection forms and kept in a locked file cabinet in Room 101 of Epler Hall at Portland State University. The data will be stored for 6 years after completion of the study and then will be destroyed (December 2015).

Any lesson plans or assignments that you choose to share with the researcher, such as your implementation plans at the end of the Creeks and Kids Workshop, will not have your name on it when it becomes part of this research. This data will be subject to the same black-out process described for confidential coding. The researcher, Ms. Austin, will only identify the piece of work with the confidential code number.

Our research records may be reviewed and/or copied by the Portland State Institutional Review Board.

\section{COSTS:}

There is no cost to you for your participation in this study. There is also no cost if you choose not to participate.

\section{PARTICIPATION:}

If you have any questions regarding your rights as a project participant, you may contact the Human Subjects Research Review Committee, Office of Research and Sponsored Projects, Unitus Building, $6^{\text {th }}$ Floor, Portland State University, (phone). If you have any questions about the study itself, contact the researcher, Tiffany Austin, (address), (phone), or the head of the Center for Science Education and advisor of the researcher, Dr. William Becker, (phone), (address), (phone).

You do not have to participate in this or any research study. If you do participate, and later change your mind, you may quit at any time. If you refuse to participate or withdraw early from 
the study, there will be no penalty or loss of any benefits to which you are otherwise entitled, and it will in no way compromise your relationship with Jackson Bottom Wetlands Preserve or Portland State University. We will provide you with a copy of the consent form.

Thank you for your consideration,

\section{Tiffany Bridgette Austin}

Master's of Science Teaching Candidate

Center for Science Teaching — Portland State University

\section{SIGNATURE:}

Your signature below indicates that you have read this entire form and that you agree to participate in this study.

Name of Participant 


\section{Informed Consent for Formal and Non-formal Educators}

\section{Dear Educator:}

Your signature indicates that you have read and understand the above information and agree to take part in this research. Please understand that you may withdraw your consent at any time without penalty, and that by signing, you are not waiving any legal claims, rights or remedies or compromising your relationship with Portland State University or Jackson Bottom Wetlands Preserve. The researcher will provide you with a copy of the informed consent letter for your own records.

Yes, I agree to participate in this research.

Specifically, I am consenting to allow the Center for Science Education researcher to collect the following sources of data from me (check all that apply):

Copies of lesson plans and other curriculum and assignments related to Creeks and Kids

$\square$ Introductory survey or interview

Creeks and Kids workshop pre-post survey

$\square$ Notes from workshop observations

$\square$ Notes from focus interviews

$\square$ Notes from informal conversations

$\square$ Interviews during the Workshop and a fall follow-up

$\square$ Teacher evaluations of Creeks and Kids workshop provided by Jackson Bottom staff

$\square$ Audio recordings from focus interviews and/or informal conversations

Name of Participant 